\title{
Método Curve Number - pesquisas e discussões dos parâmetros valor CN e abstração inicial
}

\author{
Curve Number Method - results and discussion of $\mathrm{CN}$ value \\ parameters and initial abstraction
}

\author{
Fabio Carvalho '10, Silvio Carlos Rodrigues 11 (1) \\ 'Instituto Federal de Goiás, Departamento de Áreas Acadêmicas I, Goiânia, GO, Brasil \\ " Universidade Federal de Uberlândia, Instituto de Geografia, Uberlândia, MG, Brasil
}

\section{RESUMO}

O estudo de condições de resposta ao processo de precipitação e geração de escoamento é um dos desafios em estudos hidrogeomorfológicos. Entre estudos existentes, o Método CN tornou-se importante devido à sua facilidade de aplicação a partir da utilização de parâmetros físicos, de uso e ocupação da terra e de dados de chuva, estimando o escoamento superficial e o armazenamento potencial de bacias hidrográficas, fornecendo informações hidrológicas para a tomada de decisões. Este trabalho objetiva apresentar aspectos históricos e de desenvolvimento do Método $\mathrm{CN}$, bem como pesquisas e discussões do parâmetro principal da metodologia conhecido como valor CN e da abstração inicial (la), segundo revisão de literatura. Os valores CN contidos em tabelas e gráficos do Natural Resources Conservation Service (NRCS) consideram o índice de la $=0,2$, todavia, pesquisas indicam variações nos índices de la. Valores $\mathrm{CN}$ e índices de la podem ser conseguidos mediante dados de precipitação e de escoamento superficial obtidos em bacias hidrográficas e por experimentos com chuvas artificiais em parcelas experimentais, fornecendo informações locais. Abordagens utilizando pesquisas e experimentos regionais demonstram que podem melhorar os parâmetros do Método CN para algumas regiões, gerando melhor estimativa do escoamento superficial. Os índices de abstração inicial alteram o escoamento superficial estimado pela metodologia, e pesquisas indicam que o índice de la=0,2 ser elevado para algumas condições edafoclimáticas.

Palavras-chave: Abstração inicial; Escoamento superficial; Método Curve Number; Valor CN

\section{ABSTRACT}

The study of response conditions to the precipitation process and generation of surface runoff is one of the challenges in hydrogeomorphological studies. Among existing studies, the $\mathrm{CN}$ method has become important due to its ease of application from the use of physical parameters, land use and occupation and rainfall data, estimating the runoff and potential storage of watersheds, providing hydrological 
information for decision-making by managers and researchers. This work aims to present historical aspects and development of the $\mathrm{CN}$ Method, as well as researches and discussions of the main parameter of the methodology known as $\mathrm{CN}$ value and the initial abstraction, by means of a literature review. The $\mathrm{CN}$ values contained in the tables and graphs of the Natural Resources Conservation Service (NRCS) consider the initial abstraction index as $20 \%$ of the maximum water storage capacity of the soil, however, surveys indicate variations in this index of initial abstraction. $\mathrm{CN}$ values and initial abstraction indexes can be achieved by precipitation and runoff data collected in river basins and by experiments with artificial rains in experimental plots, providing local information. Approaches using regional surveys and experiments demonstrate that they can improve the parameters of the CN Method for some regions, generating a better estimate of the surface Runoff. The initial abstraction indexes alter the surface runoff estimated by the methodology, and research indicates that the index of $1 a=0,2$ be elevated for some edaphoclimatic conditions.

Keywords: Initial abstraction; Surface runoff; Curve Number Method; CN value

\section{INTRODUÇÃO}

O Método Curve Number (Método CN) foi desenvolvido pelo Serviço de Conservação dos Solos (SCS) dos EUA desde a década de 1930, a partir da necessidade de conhecimento dos processos hidrológicos (escoamento superficial e capacidade de armazenamento de água pelo solo) em bacias hidrográficas de pequeno porte, constituindo uma ferramenta auxiliar para pesquisadores e para gestores na conservação dos solos e dos recursos hídricos. Percebeu-se a necessidade de obtenção de dados hidrológicos e o estabelecimento de procedimentos simples para a estimativa das taxas de escoamento superficial em bacias hidrográficas. O Método $\mathrm{CN}$ foi concebido com o objetivo de conhecer e de investigar o processo de escoamento superficial da água em bacias hidrográficas, a fim e se conseguir melhor controle dos processos erosivos e das perdas de solos. Inicialmente, foram obtidos dados de infiltração em várias bacias hidrográficas estadunidenses durante os anos de 1930 e de 1940 (USDA-NRCS, 2016; WOODWARD, D.E. et al., 2002).

Desenvolvido para o conhecimento prático dos processos hidrológicos em bacias hidrográficas, o Método $\mathrm{CN}$ popularizou-se mundo afora com inúmeros estudos realizados com o objetivo de ajustes de seus parâmetros e para a melhor aplicabilidade do Método CN, considerando as mais diversas condições edafoclimáticas encontradas. Os parâmetros do Método CN são objeto de estudos, 
e pesquisas são desenvolvidas a fim de estabelecer novos valores para os seus parâmetros, melhorando seus resultados, como os estudos do parâmetro CN (valor CN), da abstração inicial (la) e o índice de abstração inicial ( $\lambda$ ). $\mathrm{O}$ valor $\mathrm{CN}$ indica a probabilidade de ocorrência do escoamento superficial em um determinado uso e ocupação da terra para uma bacia hidrográfica. O parâmetro CN dá-se em função da capacidade de armazenamento de água do solo (S). Assim, solos com alta capacidade de armazenamento de água possuem baixos valores $\mathrm{CN}$ e vice-versa. Atualmente, softwares de geoprocessamento e outros programas computacionais incorporam o método às suas ferramentas de estudo de bacias hidrográficas, auxiliando pesquisadores e gestores na tomada de decisões (AUERSWALD; HAIDER, 1996; BANASIK; WOODWARD, D., 2010; D'ASARO; GRILLONE, 2012; ELHAKEEM; PAPANICOLAOU, 2009, 2012; HAWKINS, R. H., 1993; LAL, M. et al., 2016; PANDIT et al., 2009; SOULIS; VALIANTZAS, 2012; USDA-NRCS, 1986; VILLARÁN SAN JUAN, DE, 2006).

O valor CN é uma combinação das variáveis textura do solo, cobertura da bacia hidrográfica e práticas de conservação adotadas, o denominado complexo solo-cobertura vegetal. Outro parâmetro importante na aplicação do Método CN, denominado abstração inicial (la) - é uma parcela da precipitação que ocorre antes do início da formação do escoamento superficial - e também constitui-se em objeto de estudo de diversas pesquisas no mundo, pois os resultados indicam que o índice de $20 \%$ da capacidade de armazenamento de água do solo - estipulado pelo SCS, atual Natural Resources Conservation Service (NRCS) - seja muito elevado ou mesmo sofra grandes variações, podendo superestimar ou subestimar o escoamento superficial determinado pelo Método Curve Number, necessitando de estudos que indiquem uma melhor razão entre a abstração inicial (la) e a capacidade de armazenamento de água (S), ou mesmo se há relação entre esses dois fatores (Ia e S) (BALTAS; DERVOS; MIMIKOU, 2007; D'ASARO; GRILLONE, 2010; JIANG, 2001; LIM et al., 2006; LING; YUSOP, 2014; MELLO, C. R. De et al., 2003; SHI et al., 2009; WOODWARD, D. E. et al., 2003; YUAN et al., 2014). 
A variável tempo não foi incluída na metodologia do SCS por não dispor de dados de infiltração em função do tempo para os variados tipos de solo, usos e ocupação da terra, e as condições da cobertura da bacia hidrográfica. Assim, a variação da intensidade de chuva no tempo seria outro fator necessário de incorporação às equações do Método CN (COWAN, 1957 apud WOODWARD et al., 2002). Também, outra severa crítica faz-se devido à metodologia não incluir a declividade em seus procedimentos na determinação do escoamento superficial e na definição da capacidade de armazenamento de água do solo.

Este trabalho objetiva apresentar o Método Curve Number, seus aspectos históricos e seu desenvolvimento, enfatizando as pesquisas e as discussões dos parâmetros valor CN e abstração inicial. Pesquisas que estabeleçam novos valores CN e índices de abstração inicial mais precisos são necessárias e podem aumentar a eficácia do método nas regiões onde ele é aplicado. O artigo apresenta como estrutura o processo de desenvolvimento do Método $\mathrm{CN}$, abordando os fatores e as variáveis da evolução da metodologia, como: o uso da terra e as classes de tratamento do solo; a condição hidrológica; o grupo hidrológico do solo; a condição antecedente de umidade e a abstração inicial. Em cada item são apresentados pesquisas e trabalhos de cada fator e variável do Método $\mathrm{CN}$, enfatizando os valores $\mathrm{CN}$ tabelados, os valores $\mathrm{CN}$ empíricos obtidos a partir dados locais e o índice de abstração inicial.

\section{DESENVOLVIMENTO}

De acordo com Tucci (2009), a relação entre precipitação total e a precipitação efetiva (escoamento superficial) foi expressa por meio de equações desde os anos 1960, como a relação estabelecida por Kohler e Richards entre chuva e o escoamento superficial durante uma cheia. O método Curve Number foi desenvolvido para determinar o escoamento superficial e a capacidade de armazenamento de água de uma bacia hidrográfica com a utilização de poucos 
dados, e que são de fácil obtenção. Para o desenvolvimento da metodologia, o SCS realizou pesquisas para o conhecimento do processo de escoamento superficial (e outros dados hidrológicos) em bacias hidrográficas dos EUA.

O SCS contratou consultores que estudaram a retenção de água no solo e o volume de escoamento superficial produzidos em uma determinada unidade de solo durante um determinado evento pluviométrico. Seus consultores logo perceberam o impacto proporcionado pelos processos erosivos nos solos provocados pela água, pelos ventos -, ocasionando a redução da capacidade da terra em sustentar a produtividade agrícola e a própria sustentabilidade das comunidades rurais (USDA-NRCS, 2016). Salienta-se que o SCS foi criado nos esforços de recuperação da economia do New Deal de 1932, com o objetivo de desenvolver um mecanismo para a conservação dos solos e dos recursos hídricos, criando-se fundos para combater a erosão dos solos e melhorar a produtividade agrícola.

A partir de então, os especialistas do SCS desenvolveram projetos para a compreensão científica dos processos erosivos e para o desenvolvimento de práticas de conservação do solo eficazes, como a criação de viveiros de plantas regionais para selecionar e aumentar as sementes, produzindo plantas necessárias para os trabalhos de revegetação, e a consequente conservação dos solos e da água (USDA-NRCS, 2016). Inicialmente, para o desenvolvimento do Método CN, foram obtidos dados de infiltração em várias bacias hidrográficas ao longo dos anos 1930 e 1940 (WOODWARD, D.E. et al., 2002).

A citação a seguir exemplifica os procedimentos para o desenvolvimento do método Curve Number, quando em 1942 Sherman, incluiu “[...] informações adicionais traçando o escoamento superficial versus a precipitação com curvas separadas para cada mês e um ajuste tabular para a precipitação antecedente" (USDA-NRCS, 2004, p. 1). Em 1951, as proposições de Sherman foram ampliadas com o diagrama de correlação múltipla proposta por Kohler e Linsley, incorporando ao desenvolvimento do método itens como precipitação 
antecedente, época do ano, características da precipitação, também incluindo os dados básicos de precipitação total e de escoamento superficial (BANASIK et al., 2014; USDA-NRCS, 2004a).

De acordo com Woodward et al. (2002), em 1954, ao agrupar dados de infiltração do Texas, de Oklahoma, do Arkansas e da Louisiana, Andrews descobriu que a textura do solo foi fator determinante no processo de escoamento superficial para os eventos pluviométricos analisados. Andrews criou um gráfico para a estimativa do escoamento superficial direto a partir da combinação das variáveis textura do solo, cobertura da bacia e práticas de conservação utilizadas, denominado complexo solo-cobertura vegetal (soil-cover complex). O soil-cover complex constituiu um grande avanço para o desenvolvimento do Método $\mathrm{CN}$, permanecendo como parte dos procedimentos na atualidade.

Prosseguindo no histórico do desenvolvimento do Método CN, em 1955, os solos foram a classificados por Musgrave, levando-se em consideração a taxa de infiltração. Assim, os solos foram agrupados levando em consideração a capacidade mínima de infiltração, determinadas por meio de testes de laboratórios e pela textura. Os solos foram agrupados em A (arenosos), B, C e D (argilosos). Desde então, foram classificados 14.000 grupos de solos nos Estados Unidos. Atualmente, esse sistema de classificação hidrológica dos solos constitui-se fundamental para aplicação do método do Curve Number (MUSGRAVE, 1955; WOODWARD, D.E. et al., 2002).

De acordo com o USDA-NRCS (2004a), para o estabelecimento da equação geral do Método CN, Mockus partiu da premissa de que o gráfico representando dados de precipitação total e de escoamento superficial para várias chuvas em uma determinada bacia hidrográfica é côncavo, e que, em pequenos eventos pluviométricos não há escoamento superficial. Com o aumento da intensidade da chuva, a curva torna-se assintótica a uma linha paralela a uma linha de igualdade. Mockus, em 1949, sugeriu que o escoamento superficial fosse inferido com base nos seguintes fatores: tipo de solo, extensão da área, localização, uso da terra, 
precipitação antecedente, duração e profundidade do evento pluviométrico, temperatura média anual e época da chuva. Mockus, então, propôs uma equação que representasse a curva contida no gráfico da precipitação versus o escoamento superficial. Inicialmente, ele desconsiderou a abstração inicial, propondo uma curva adequada para a relação entre a chuva, o escoamento superficial e o potencial de retenção de chuva por meio da Equação 1:

$$
\frac{F}{S}=\frac{Q}{P}
$$

Em que:

$\mathrm{F}=$ retenção de água após o início do escoamento superficial $(\mathrm{mm})$;

$\mathrm{S}=$ potencial máximo de retenção depois de iniciado o escoamento superficial $(\mathrm{S} \geq \mathrm{F})(\mathrm{mm})$;

$\mathrm{Q}=$ escoamento superficial $(\mathrm{mm})$;

$\mathrm{P}=$ Precipitação $(\mathrm{mm})$.

Fonte: (USDA-NRCS, 2004a)

Posteriormente, Mockus propôs um valor para retenção d'água após o início do escoamento superficial ' $F$ ', satisfazendo a Lei da Conservação das Massas (Equação 2).

$$
F=P-Q
$$

Substituindo F da Equação 1 pela Equação 2, obtém-se:

$$
\frac{P-Q}{S}=\frac{Q}{P}
$$

Isolando-se Q da Equação 3, tem-se:

$$
Q=\frac{P^{2}}{P+S}
$$

Observe que no emprego da Equação 4, para a obtenção do escoamento superficial, atribui-se zero para a abstração inicial. Quando a abstração inicial não é zero, 'P' da Equação 1 é substituído por 'P-Ia', ou seja:

$$
\bar{F}=\frac{Q}{P-I a}
$$

Em que:

$\mathrm{F} \leq \mathrm{S}$

$\mathrm{Q} \leq$ (P-la)

Fonte: (USDA-NRCS, 2004a) 
No processo de desenvolvimento do método Curve Number, várias proposições foram criadas para simular a relação chuva-escoamento superficial, e as primeiras versões não enquadravam a abstração inicial (la), que se define como a água evaporada diretamente para a atmosfera durante e após os eventos pluviométricos, a água interceptada pela vegetação, o armazenamento superficial e a infiltração inicial, instantes antes do início do processo de escoamento superficial (runoff). Define-se a abstração inicial (la) da precipitação como a parcela de chuva produzida desde o seu início até o instante em que se inicia o processo de escoamento superficial, constituindo-se, portanto, parte da chuva que fica retida na superfície, em depressões, na copas da árvores e que não contribui com o escoamento superficial (BALTAS; DERVOS; MIMIKOU, 2007; HAWKINS, R. H.; KHOJEINI, 2000; LING; YUSOP, 2014; MELLO, C. R. De et al., 2003; WOODWARD, D. E. et al., 2003; WOODWARD, D.E. et al., 2002; YUAN et al., 2014). Incorporando a abstração inicial à Equação 2 e substituindo-se a incógnita ' $P$ ', obtém-se:

$$
F=(P-I a)-Q
$$

Posteriormente, substitui-se a incógnita ' $F$ ' da Equação 5, pelo valor de ' $F$ ' da Equação 6, resultando em:

$$
\frac{(P-I a)-Q}{S}=\frac{Q}{(P-I a)}
$$

Isolando a incógnita 'Q' (escoamento superficial) da Equação 7, chega-se à Equação 8 para a determinação do escoamento superficial, incorporando a abstração inicial:

$$
Q=\frac{(P-I a)}{(P-I a)+S}
$$

Em que:

$\mathrm{Q}=$ escoamento superficial $(\mathrm{mm})$;

$\mathrm{P}=$ precipitação $(\mathrm{mm})$;

$l a=$ abstração inicial $(\mathrm{mm})$;

$\mathrm{S}=$ capacidade de armazenamento de água do solo $(\mathrm{mm})$.

Fonte: (USDA-NRCS, 2004a) 
Com a incorporação da abstração inicial, a Equação Geral do Método CN estabeleceu-se por meio de estudos da relação entre a abstração inicial e a capacidade de armazenamento. A relação entre a abstração inicial e a capacidade de armazenamento foram determinadas em bases de dados obtidos em grandes e em pequenas bacias hidrográficas. Estabeleceu-se que a abstração inicial constitui $20 \%$ da capacidade de armazenamento de água do solo, ou seja, la = 0,2·S. Assumindo que a abstração inicial representa $20 \%$ da capacidade de armazenamento de água, a Equação 8 substitui-se pela Equação 9 na determinação do escoamento superficial:

$$
\begin{array}{cc}
Q=\frac{(P-0,2 S)^{2}}{P+0,8 S} & \text { Se } P>I a \\
Q=0 & \text { Se } P<I a
\end{array}
$$

Fonte: (USDA-NRCS, 2004a)

A capacidade de armazenamento de água em milímetros obtém-se em função do valor CN, com o emprego da Equação 11:

$$
S=\frac{25400}{C N}-254
$$

Em que:

$\mathrm{S}=$ capacidade de armazenamento de água do solo $(\mathrm{mm})$;

$\mathrm{CN}=$ valor curve number .

Fonte: (USDA-NRCS, 2004a)

A cada complexo solo-cobertura vegetal (soil-cover complex) atribui-se um valor $\mathrm{CN}$ preestabelecido em gráficos e em tabelas. $\mathrm{O}$ valor $\mathrm{CN}$ indica o potencial de escoamento superficial para cada complexo, variando de zero a 100, onde, teoricamente, o valor zero é atribuído para áreas com baixo poder de produzir escoamento superficial e elevada capacidade de armazenamento de água, e o valor de 100 volta-se para áreas com alto poder de produzir escoamento superficial e reduzida capacidade de armazenamento do água (HAWKINS, R. H., 1993; HAWKINS, R. H. et al., 2010; HAWKINS, Richard H. et al., 2009; USDA-NRCS, 2004a; WOODWARD, D.E. et al., 2002). 
Pesquisas são desenvolvidos para aprimorar o Método CN com modificações de seus parâmetros para cálculos do escoamento superficial a partir de dados de precipitação. Os resultados calculados com base no Método CN modificado apresentou melhores resultados do volume de escoamento superficial que se comparados ao método original, ou seja, os resultados do escoamento superficial observado na bacia foram mais próximos ao volume de escoamento superficial calculados com método $\mathrm{CN}$ modificado se comparados aos dados do escoamento superficial do método CN original (WALEGA; SALATA, 2019).

Programas de geoprocessamento são utilizados para a estimativa do escoamento superficial e para o cálculo do tempo de concentração da bacia utilizando-se da metodologia SCS-CN. Neste processo cada área da bacia hidrográfica recebe um valor $\mathrm{CN}$ e a partir da precipitação determina-se o escoamento superficial (BESKOW et al., 2009; FEITOSA et al., 2010; FELIZARDO, 2016; MATA-LIMA et al., 2007; POMPERMAYER, 2013). De acordo com Beskow et al. (2009), a partir do mapa de infiltração da bacia hidrográfica definiu-se o mapa do grupo hidrológico do solo. Através do mapa de uso e ocupação da terra definiu-se o complexo solo-cobertura vegetal, e por conseguinte, os valores CN's.

O modelo HEC-HMS - Hydrologic Engeneering Center - Hydrologic Modeling System incorpora o Método SCS-CN no processo de modelagem hidrológica, e o modelo HEC-HMS é incorporado a alguns softwares de geoprocessamento. $O$ modelo HEC-HMS simula os processos de precipitação, evaporação e escoamento em bacias hidrográficas dendríticas. O programa ArcView 3.10.1 possui a extensão HEC-GeoHMS que possibilita "[...] delinear automaticamente bacias hidrográficas e linhas de água a partir de imagens de satélite ou dos Modelos Digitais do Terreno (SANTOS et al., 2006)". A seguir, apresentam-se os principais fatores utilizados para determinar o valor $\mathrm{CN}$. 


\subsection{Os fatores e as variáveis do valor $\mathrm{CN}$}

Os valores CN indicados pelas tabelas e gráficos do NRCS representam um parâmetro de retenção de águas pluviais em uma bacia hidrográfica, e indicam a capacidade de um dado uso e ocupação da terra em produzir escoamento superficial. Os valores $\mathrm{CN}$ para os usos da terra caracterizados como urbanos são maiores que os valores $\mathrm{CN}$ geralmente encontrados em usos da terra rural (USDANRCS, 2004a).

Vários fatores são levados em consideração na definição do parâmetro CN, como o 'uso da terra' e as 'práticas de cultivo', a 'condição hidrológica', o 'grupo hidrológico do solo' e as 'condições antecedentes de umidade'. De acordo com Ponce e Hawkins (1996), as experiências práticas têm mostrado que a definição dos valores CN para os usos e ocupação da terra mais prováveis variam em um intervalo que se estende do $\mathrm{CN}=40$ ao $\mathrm{CN}=97$, constituindo em uma vantagem na sua definição, devido à redução dos possíveis valores $\mathrm{CN}$ para um determinado estudo. Portanto, a determinação do valor CN para um determinado uso e ocupação da terra ou para uma bacia hidrográfica constitui-se em um exercício empírico a partir de um modelo conceitual.

Os valores CN formam uma combinação particular das características de uso e ocupação da terra e de solos, denominados complexo solo-cobertura vegetal (soil-cover complex), obtidos por meio de um gráfico onde representava o maior escoamento anual frente a eventos pluviométricos. Essa relação foi estabelecida para os diversos complexos solo-cobertura vegetal. A mediana dos dados foi adotada como representativa para aquela bacia hidrográfica, e, quando houve duas ou mais bacias de mesma representatividade, utilizou-se a média de todas as bacias analisadas com o mesmo soil-cover complex (USDA-NRCS, 2004b; WOODWARD, D.E. et al., 2002). 
2.1.1 Uso da terra e classes de tratamento do solo

O uso da terra e as classes de tratamento do solo são utilizadas para determinar o complexo hidrológico solo-cobertura vegetal. Os impactos do uso da terra e das práticas de cultivo agrícola em uma bacia hidrográfica, no processo de precipitação e de escoamento superficial são utilizados para determinar o valor CN para aquele específico complexo solo cobertura-vegetal. O uso da terra inclui a cobertura da bacia hidrográfica, o tipo de vegetação, as áreas de bosques, de pastagens, as áreas agrícolas, de solo exposto, bem como áreas alagadas e/ou pantanosas, e áreas urbanas e rodovias. As classes de tratamento referem-se à adoção de práticas mecânicas como os terraços e as curvas de nível, e as práticas de gestão como a rotação de cultura e o pastoreio. As práticas de cultivo podem ser conhecidas mediante observação e pelo levantamento da vegetação da bacia hidrográfica (D'ASARO; GRILLONE, 2010; USDA-NRCS, 2002; VILLARÁN SAN JUAN, DE, 2006; WOODWARD, D.E. et al., 2002).

Temos áreas de florestas que são subdivididas em áreas florestadas do Oeste e do Leste dos EUA. Para as áreas florestais do leste americano, o grupo hidrológico, o tipo de matéria orgânica e a profundidade são os principais fatores na definição do valor CN. Já para o oeste, os fatores determinantes do valor CN são o grupo hidrológico, o tipo e a densidade de vegetação (arbusto, herbáceos, pinus etc.).

\subsubsection{Condição hidrológica}

A condição hidrológica caracteriza-se pela combinação de fatores que influem na infiltração e no escoamento superficial. Os diversos tipos de cobertura do solo (pastagens; campos agrícolas; bosques, áreas impermeáveis) são classificados nas seguintes condições hidrológicas: poor, fair e good. Para a classificação, fatores são considerados a exemplo do tipo de cobertura vegetal (pastagem, agricultura), sua densidade e variação ao longo do ano e o grau de 
compactação da superfície. Outras características devem ser observadas como formação de dossel e o tipo de cultivo (EPPS et al., 2013; USDA-NRCS, 2004b). Portanto, uma boa condição hidrológica aplica-se às áreas que favoreçam a infiltração e reduzam o escoamento superficial.

No outro extremo, encontram-se áreas que possuem baixa capacidade de infiltração e alta propensão para a formação do escoamento superficial, denominadas pobres. De acordo com o USDA-NRCS (2004b), a densidade da cobertura vegetal da área define a condição hidrológica, e áreas com mais de $20 \%$ de cobertura vegetal são definidas como 'boas'. Nas áreas de pastagens, define-se a condição hidrológica determinada pela porcentagem de área recoberta por gramíneas, variando em pobre, regular e bom. Outra forma de estimar a condição hidrológica consiste em avaliar a quantidade de matéria seca por área, onde quanto maior a quantidade de matéria seca melhor consiste na condição hidrológica (USDA-NRCS, 2004b; VILLARÁN SAN JUAN, DE, 2006).

\subsubsection{Grupo hidrológico do solo}

O NRCS definiu quatro grupos hidrológicos do solo (HSG's - Hydrologic Soil Groups) em função de dados de precipitação, escoamento superficial e de infiltração. Os grupos hidrológicos são definidos a partir da seguinte hipótese: os solos dentro de uma mesma região climática, que possuem características físicas semelhantes, como profundidade das camadas, taxa de percolação da água, a textura e a estrutura, o grau de dilatação quando saturado, possuirão padrões semelhantes de escoamento superficial (MUSGRAVE, 1955; STEWART; CANFIELD; HAWKINS, R., 2011; USDA-NRCS, 2009).

Os grupos hidrológicos foram definidos conforme a percolação da água nas camadas do solo com a menor condutividade hidráulica saturada e pela profundidade das camadas impermeáveis ao longo de seu perfil. Portanto, a localização ao longo do perfil da camada com menor condutividade hidráulica é 
utilizada para determinar o grupo hidrológico. Salienta-se que, em alguns casos, dados de condutividade hidráulica não são disponíveis, outras informações como textura, compactação e estrutura, composição mineralógica e a matéria orgânica poderão ser utilizados para o enquadramento do solo em um dado grupo (USDANRCS, 2009). Na Tabela 1 observa-se os quatro grupos hidrológicos, a textura e a taxa de infiltração correspondendo a cada HSG's definidos pelo NRCS.

Tabela 1 - Grupo hidrológico do solo (HSG's)

\begin{tabular}{ccc}
\hline GRUPO HIDROLÓgICo SOLO & TEXTURA & $\begin{array}{c}\text { CAPACIDADE DE } \\
\text { INFILTRAÇÃO (SOLO } \\
\text { EXPOSTO) }\end{array}$ \\
\hline A & $\begin{array}{c}\text { Areia, areno-argilosa ou } \\
\text { franco-arenosa } \\
\text { B }\end{array}$ & Maior que 0,30 pol./h. \\
C & $\begin{array}{c}\text { Silto-argilosa ou argilosa } \\
\text { Argilo arenosa }\end{array}$ & 0,15 a 0,30 pol./h. \\
D & $\begin{array}{c}\text { Silto-argilosa, Argilo-siltosa, } \\
\text { Argilo-arenosa, siltosa } \\
\text { Argila }\end{array}$ & 0,05 a 0,15 pol./h. \\
& A a 0,05 pol./h. \\
\hline
\end{tabular}

Fonte: USDA-NRCS (1986, Apêndice A)

Os solos do grupo A possuem elevada condutividade hidráulica saturada e lençol freático muito profundo, e no extremo temos os solos do grupo D, classificados como baixa condutividade hidráulica saturada e com lençol freático superficial. O USDA-NRCS (1986), refere-se a taxa de infiltração e a taxa de transmissão, sendo a primeira a taxa na qual a água entra no solo, influenciado pela condições da superfície e a segunda a taxa em que água se move dentro do solo. A taxa de transmissão é maior nos solos do grupo A que possuem melhores condições de infiltração e a taxa de transmissão é menor em solos do grupo $D$ que possuem piores condições de infiltração (Tabela 1).

Em uma pesquisa os HSG's e os valores CN's foram determinados a partir de dados de precipitação e de escoamento superficial de bacias hidrográficas do semiárido norte-americano, que posteriormente foram comparados com os 
valores CN disponibilizados nas tabelas do NRCS/USDA, considerando o grupo hidrológico. A partir de informações do HSG e dos valores CN obtidos nos manuais do NRCS/USDA e, em seguida, comparados com valores CN obtidos a partir de dados de precipitação-escoamento superficial, mostrou-se uma fraca correlação nos valores $\mathrm{CN}$, sugerindo que a determinação 'HSG-CN' seria imprecisa. Os autores sugerem a estimativa dos valores $\mathrm{CN}$ com base em dados de precipitaçãoescoamento superficial ao invés de valores $\mathrm{CN}$ determinados a partir de propriedade dos solos (STEWART; CANFIELD; HAWKINS, 2011). Em um outro trabalho apresentado por Teegavarapu e Chinatalapudi (2018), avalia-se a influência do lençol freático na determinação do HSG e, consequentemente, na determinação dos valores CN.

\subsubsection{Condição antecedente de umidade}

O parâmetro condição antecedente de umidade (AMC) refere-se às condições de umidade do solo, alterando o valor CN conforme a AMC que se divide em: AMC I; AMCII e AMC III. De acordo com a classificação dos solos, nas três categorias, há alterações nos valores CN. O AMC II representa as condições médias de umidade, o que corresponde a $50 \%$ de saturação do solo antes de um evento pluviométrico. A condição do solo seco corresponde ao AMC I, e o AMC III o solo encontra-se totalmente saturado. A definição da condição antecedente de umidade obtém-se com a determinação da precipitação dos cinco dias anteriores ao evento analisado (ALI; GHOSH; SINGH, R., 2010; D'ASARO; GRILLONE, 2012; LAL, M.; MISHRA; PANDEY, A., 2015; MISHRA; JAIN; SINGH, V. P., 2004; USDA-NRCS, 2004a).

Existem possibilidades de variação do valor CN que são difíceis de quantificar, pois dependem de variáveis do ciclo hidrológico que afetam o processo de infiltração, como: "[...] a intensidade de tempestades, temperatura, tempo de 
concentração, evapotranspiração e umidade do solo (RALLISON; MILLER, 1982 apud DE VILLARÁN SAN JUAN, 2006, p.19)".

A condição antecedente de umidade I (AMC I) corresponde a 10\% de probabilidade de ocorrer escoamento superficial a partir de um evento pluviométrico. Como mencionado, o AMC II corresponde a 50\%, e o AMC III representa $90 \%$ de probabilidade de que um evento de escoamento superficial ocorra. Segundo o USDA-NRCS (2004a), os dados obtidos em uma bacia hidrográfica em lowa (EUA) indicam que não há uma relação explícita entre a precipitação antecedente e a capacidade de armazenamento de água pelo solo.

Atualmente, a AMC foi transformada em condição antecedente de escoamento superficial (ARC) devido à precipitação antecedente explicar apenas parte das variações que os valores $\mathrm{CN}$ podem apresentar. O valor $\mathrm{CN}$ varia em função da intensidade, da duração e do total da precipitação, devido às condições de umidade, densidade da cobertura vegetal, do estado de crescimento do vegetal e da temperatura (D'ASARO; GRILLONE, 2012; USDA-NRCS, 2004a).

Essas variações do valor CN foram denominadas de ARC, subdividida em três grupos: ARC I, ARC II e ARC III. A condição média de ocorrer o escoamento superficial corresponde ao ARC II, o ARC I às condições de solos secos e o ARC III às condições de maior umidade. Portanto, O ARC I| corresponde às condições médias de probabilidade de ocorrência do escoamento superficial, o ARC I corresponde a $10 \%$ de probabilidade de que ocorra o escoamento superficial e o ARC III corresponde a $90 \%$ de probabilidade de que ocorra o escoamento superficial (USDA-NRCS, 2004a; WOODWARD, D.E. et al., 2002).

De acordo com Lal, Mishra e Pandey (2015), a determinação do valor CN com base na AMC determinada por meio da precipitação antecedente em 5 dias apresentou menor desempenho na estimativa do escoamento superficial do que condição antecedente de umidade determinada por medidas diretas de umidade do solo anteriormente ao evento de precipitação analisado. Comparado ao escoamento superficial obtido pelo Método $\mathrm{CN}$ nas duas possibilidades de 
determinação do valor $\mathrm{CN}$ (precipitação antecedente de 5 dias ou umidade antecedente do solo), com o escoamento superficial observado nas parcelas experimentais, o escoamento superficial determinado pelo valor $\mathrm{CN}$ selecionado por meio da AMC obtida com a umidade do solo melhor aproximou-se do escoamento superficial observado nas parcelas experimentais quando comparado à $\mathrm{AMC}$ determinada pela precipitação antecedente de 5 dias.

\subsection{Pesquisas dos valores $\mathrm{CN}$}

O valor CN pode ser estimado por meio das tabelas do NRCS e de outras fontes. No entanto, os valores $\mathrm{CN}$ podem ser determinados por meio de dados de precipitação e de escoamento superficial (P-Q) obtidos em bacias hidrográficas e mediante emprego de métodos estatísticos (AJMAL; KIM, 2015; BANASIK et al., 2014; BANASIK; WOODWARD， D., 2010; D'ASARO; GRILLONE， 2012; ELHAKEEM; PAPANICOLAOU, 2009; EPPS et al., 2013; HAWKINS, R. H. et al., 2010; LAL, M. et al., 2016; MISHRA et al., 2014; OLIVEIRA et al., 2016; PANDIT et al., 2009; SOULIS; VALIANTZAS, 2012; STEWART; CANFIELD; HAWKINS, R., 2011).

Por meio das tabelas do NRCS, seleciona-se o valor CN pela indicação das características físicas e de uso e ocupação da terra da bacia hidrográfica (denominado complexo solo-cobertura vegetal), podendo ser urbanas, rurais, florestadas etc. Os valores CN disponibilizados pelo NRCS são para a abstração inicial a $20 \%$ da capacidade de armazenamento de água do solo $(\lambda=0,2)$. Considerando a $\mathrm{I} a=0,2 \cdot \mathrm{S}$ o valor $\mathrm{CN}$ pode ser estimado por meio de dados 'P-Q' para pequenas bacias hidrográficas com a aplicação da Equação 12:

$$
S=5\left(P+2 Q-\sqrt{\left(4 Q^{2}+5 P q\right)}\right)
$$

Onde:

$\mathrm{S}=$ capacidade de armazenamento de água do solo $(\mathrm{mm})$;

$\mathrm{P}=$ precipitação $(\mathrm{mm})$;

$\mathrm{Q}=$ escoamento superficial $(\mathrm{mm})$

Fonte: Hawkins et al. (2009); Hawkins, Hjelmfelt e Zevenbergen (1985) 
A Equação 12 é uma derivação da Equação Geral do Método SCS-CN, considerando a abstração inicial como $20 \%$ da capacidade de armazenamento de água do solo. Na pesquisa desenvolvida por Hawkins, Hjelmfelt e Zevenbergen (1985), apenas grandes eventos pluviométricos foram acatados e considerou-se a precipitação antecedente, tomando o valor $\mathrm{CN}$ como pertencente à condição antecedente de umidade I, II ou III. Em determinados eventos pluviométricos, o escoamento superficial só ocorre se o valor CN estiver na condição II ou III, e não ocorre na condição antecedente de umidade I.

Um estudo foi desenvolvido objetivando avaliar valores $\mathrm{CN}$ para coberturas florestais (bosques) no estado da Carolina do Sul (EUA) utilizando dados de precipitação e de escoamento superficial obtidos in locus. Esses dados foram comparados com os valores $\mathrm{CN}$ obtidos nas tabelas do NRCS. Os valores CN derivados de dados 'P-Q' para as bacias hidrográficas analisadas variaram de 46 a 90 para uma das bacias, e de 42 a 89 em uma outra bacia analisada. Os resultados da pesquisa com as bacias hidrográficas mostraram uma melhora na determinação do escoamento superficial com a utilização de valores $\mathrm{CN}$ ajustados mediante a avaliação das condições antecedentes de escoamento superficial, o qual, por sua vez, baseia-se no nível do lençol freático (EPPS et al., 2013).

A elevação do nível do lençol freático foi correlacionada em função das alterações sazonais na evapotranspiração, como, por exemplo, a elevação do lençol freático e as condições de umidade durante os meses de inverno, quando observam-se as taxas de evapotranspiração reduzidas, e o baixo nível do lençol freático com condições secas durante o verão, quando a evapotranspiração é elevada. Dados da flutuação do nível do lençol freático foram utilizados para as correlações entre ARC e o valor CN-derivado de dados 'P-Q'. Os valores CN derivados de dados 'P-Q' variaram dependendo do ARC no instante da precipitação, valores semelhantes aos encontrados originalmente nas tabelas do NRCS. Os valores $\mathrm{CN}$ muito baixos encontrados devem-se às condições muito secas, possivelmente relacionadas a regiões com canais intermitentes e com baixo nível 
do lençol freático. Os resultados mostraram que os valores $\mathrm{CN}$ a partir de dados de 'P-Q' podem ser menores do que os valores CN obtidos por meio do método TR55, ou seja, sem os dados hidrológicos específicos do local (EPPS et al., 2013).

Foram analisados eventos de precipitação na estação de dormência e na estação de crescimento, e os resultados mostraram que valores CN 'P-Q' (derivados de dados de precipitação e de escoamento superficial) variaram de acordo com a sazonalidade, com elevadas médias dos valores CN na estação de dormência em comparação com valores $\mathrm{CN}$ para o período de crescimento da vegetação em ambas as bacias hidrográficas analisadas, e concluem que as variações sazonais no escoamento superficial (e consequentemente no valor $\mathrm{CN}$ ) foram associadas ao ARC. Os maiores valores CN foram observados no início e no final do ano, período de dormência, e quando há o predomínio de condições úmidas e, consequentemente, maior escoamento superficial (EPPS et al., 2013).

Na região, em meados do ano, quando há o predomínio do período de crescimento da vegetação, observam-se valores $\mathrm{CN}$ mais baixos (chegando a valores $\mathrm{CN}$ próximos a 55 , ou mesmo abaixo de 50 ), com os $\mathrm{CN}$ mais baixos no verão, período de altas temperaturas e altas taxas de evapotranspiração, contribuindo para a redução do escoamento superficial e, provavelmente, um aumento da capacidade de armazenamento de água, como afirmam Sun et al. (2002) apud Epps et al. (2013).

Verificaram-se variações no valor $\mathrm{CN}$ de acordo com as tendências sazonais atribuídas à condição antecedente de escoamento (ARC) na bacia hidrográfica analisado na Carolina do Sul (EUA). De acordo com Epps et al. (2013), uma simples média do valor CN pela metodologia do NRCS pode não prever adequadamente os volumes de escoamento superficial, devido à variabilidade sazonal do valor CN. A análise entre os valores CN 'P-Q' e a precipitação antecedente de 5 dias para definir a ARC mostrou-se fraca para as bacias hidrográficas analisadas, e concluíram que o indexador criado na pesquisa (API - indexador precipitação antecedente em 5 dias) não é recomendável para determinar a ARC. Por exemplo, para API - 5 dias, 
com volume zero (ou próximo de zero) houve muita variação dos CN 'P-Q' para as bacias hidrográficas analisadas, do $\mathrm{DCN}=42$ a próximo ao $\mathrm{DCN}=80$.

A elevação do lençol freático é uma relação entre a precipitação, a evapotranspiração e a vazão na bacia hidrográfica, e a elevação do lençol freático possui influência na geração do escoamento superficial. Assim, os valores CN 'P-Q' para as bacias analisadas possuem maior relação com o nível do lençol freático do que com a precipitação antecedente em 5 dias. Como traz a citação a seguir: "Lower water table elevations are associated with lower CNs indicating that runoff generation is lower and that these conditions define dry ARC (EPPS et al., 2013, p.1293)”. Os CN ‘P-Q’ aumentam com a elevação do nível do lençol freático, e o nível d'água subterrânea mais próximo da superfície do solo indica o ARC III (ARC úmido).

Quando o nível do lençol freático estava baixo, os valores CN também foram baixos, à medida que o nível do lençol freático foi aumentando houve também aumento dos valores $C N$ ' $P$ - $Q$ ', concluindo que a fixação do valor $C N$, de acordo com a flutuação do nível do lençol freático, foi aconselhada. Houve pontos no nível do lençol freático em que os valores CN 'P-Q' aumentaram significativamente. Em uma das bacias analisadas, indicou-se o ponto em que o nível do lençol levava ao aumento do valor CN-derivado (DCN). O nível do lençol freático em uma das bacias hidrográficas era de 3,25 - 3,5 m acima do nível do mar; e na outra bacia hidrográfica, o nível do lençol freático era de 8,5 - 8,97 m acima do nível do mar. Assim, o nível do lençol freático funcionava como um limite para determinar o ARC seco e o ARC úmido para as bacias hidrográficas analisadas. Esses limites foram determinados por meio da definição do valor CN, utilizando-se o TR-55, onde CN 'P-Q' acima de 75 seriam ARC-III para as bacias hidrográficas analisadas. Já os valores CN 'P-Q' do ARC I seriam os valores CN abaixo da média dos valores CN 'P$Q^{\prime}$ para as bacias analisadas, que em uma foi $C N$ ' $P-Q$ '=70 e na outra $C N$ ' $P-Q$ '=68.

Então, o ARC-II seriam os valores CN entre 70 e 75 em uma das bacias, e na outra seriam os valores $\mathrm{CN}$ entre 68 e 75 para a outra bacia hidrográfica analisada. Os valores CN obtidos a partir de dados de precipitação-escoamento superficial 
podem variar de chuva para chuva, variar com a intensidade e a duração da chuva, o total da precipitação, as condições de umidade do solo, a cobertura, o estágio de desenvolvimento da planta e a temperatura. Estudos do efeito da precipitação antecedente nos valores CN mostraram uma fraca relação. Ainda nesse sentido, constatou-se uma variação sazonal nos valores $\mathrm{CN}$, principalmente em ambientes úmidos e raramente em bacias hidrográficas áridas e semiáridas, com altos valores CN na estação de dormência e baixos valores CN na estação de crescimento (D'ASARO; GRILLONE, 2012; WOODWARD, D.E. et al., 2002).

Uma pesquisa realizada na Ilha da Sicília (Itália) objetivou determinar o valor CN de 61 bacias hidrográficas a partir de dados de precipitação e de escoamento superficial observados ao longo de 20 anos e a partir de três diferentes metodologias: Método NEH-4; Asymtotic fitting method e o método dos mínimos quadrados. As análises indicaram altos valores CN no período de dormência, quando é menor a cobertura do solo e maior a umidade se comparada aos menores valores $\mathrm{CN}$ no período de crescimento da vegetação quando o solo está mais seco e, consequentemente, uma maior capacidade de armazenamento de água do solo. De acordo com D'asaro, Grillone, 2012 e Woodward et al. (2002), são necessários novos estudos para melhor relacionar os valores CN (escala de bacias hidrográficas) com as características físicas das mesmas, como: hidrológicas; cobertura da bacia; geomorfologia etc.

A pesquisa desenvolvida por Banasik e Woodward (2010) objetivou verificar a aplicabilidade do Método SCS-CN em bacia hidrográfica do território polonês, determinando novos valores $\mathrm{CN}$ a partir da análise de dados de eventos pluviométricos de quase 30 anos de coleta, em uma bacia hidrográfica com predomínio do uso agrícola, predominantemente composta por solos arenosos, com área de 23,4 km² em um relevo de planície no centro do país. A precipitação média anual para o período analisado na bacia correspondeu a $606 \mathrm{~mm}$, e o escoamento superficial foi de $107 \mathrm{~mm}$. Os valores $\mathrm{CN}$ foram estimados por três meios: $1^{\circ}$ conforme o uso, a ocupação da terra e o tipo de solo, para bacias 
hidrográficas sem dados meteorológicos (ungauged); $2^{\circ}$ com uso de dados de precipitação-escoamento superficial de elevada magnitude; e $3^{\circ}$ baseado em eventos de precipitação-escoamento superficial, conforme a 'abordagem assintótica' de Hawkins (1993). Foram estimados os valores CN empíricos (computados na pesquisa) e os valores CN estimados pelo Método SCS-CN para um mesmo uso e ocupação da terra, e um mesmo tipo de solo para a bacia hidrográfica analisada.

Para a determinação dos valores $\mathrm{CN}$, conforme a metodologia do NRCS, os pesquisadores utilizaram mapas topográficos com informações do uso da terra e dados estatísticos da região para determinar a cultura nas áreas de terra arável (25\% batata; $65 \%$ grãos; $10 \%$ alfafa), perfazendo $70 \%$ da área total da bacia hidrográfica. Também obtiveram mapas com informações de solos da bacia. De posse de todas as informações, o valor $\mathrm{CN}$ médio da bacia hidrográfica foi determinado de acordo com a metodologia contida no NRCS (1972).

O valor CN empírico foi determinado a partir de dados de precipitação e escoamento superficial coletados na bacia hidrográfica, aplicando-se Equação 13:

$$
\mathrm{CN}=25400 /(\mathrm{S}+254)
$$

Onde:

$\mathrm{CN}=$ valor $\mathrm{CN}$ (adimensional);

$\mathrm{S}=$ capacidade de armazenamento de água do solo $(\mathrm{mm})$.

Fonte: Hawkins (1973) apud Banasik e Woodward (2010)

A variável 'S' foi determinada a partir da Equação 14:

$$
\mathrm{S}=5\left(\mathrm{P}+2 \mathrm{H}-\left(4 \mathrm{H}^{2}+5 \mathrm{PH}\right)^{\wedge} 0,5\right)
$$

Onde:

$\mathrm{P}=$ precipitação $(\mathrm{mm})$;

$\mathrm{H}=$ escoamento superficial - precipitação efetiva $(\mathrm{mm})$;

$\mathrm{S}=$ Capacidade de armazenamento de água pelo solo.

Fonte: Idem

Os valores CN variaram de 59,9 a 97,1 ocorrendo a redução dos valores CN com aumento da precipitação incidente. Os resultados apresentaram que para precipitações maiores do que $20 \mathrm{~mm}$, os valores $\mathrm{CN}$ empíricos e os valores $\mathrm{CN}$ 
estimados foram próximos. A média do valor CN empírico foi de 82,1 - a partir dos dados de precipitação-escoamento superficial - para todos os eventos analisados foi significativamente maior que o CN teórico $(74,6)$ - estimado a partir dos dados físicos, e de uso e ocupação da terra da bacia hidrográfica analisada. O valor CN encontrado para eventos com precipitação maiores do que $30 \mathrm{~mm}(68,3)$ foi menor que o CN teórico $(74,6)$ (BANASIK; WOODWARD, D., 2010).

Os autores concluíram ser possível a utilização do Método SCS-CN original na área estudada e adjacências do território polonês com as mesmas características físicas. O valor $\mathrm{CN}$ encontrado a partir dos dados coletados reduziram-se à medida que houve aumento da precipitação incidente, e variaram sazonalmente com a redução do valor $\mathrm{CN}$ durante a estação de crescimento, ou seja, o crescimento da vegetação levaria a um maior retenção de água e menor escoamento superficial, reduzindo, portanto, o valor CN (BANASIK; WOODWARD, D., 2010).

Com o objetivo de avaliar a viabilidade e a eficiência do parâmetro CN (principal parâmetro do Método SCS-CN), desenvolveram uma pesquisa na bacia hidrográfica do rio Ivaí no Estado do Paraná, que apresentava dados de chuva e vazão, bem como produtos cartográficos da área. A bacia hidrográfica do rio Ivaí possui diversos tipos de solo, como: cambissolos, latossolos, neossolos, entre outros. O clima da região varia do subtropical (alto curso da bacia hidrográfica) ao tropical (médio e baixo cursos da bacia hidrográfica). O banco de dados físicos da bacia hidrográfica foi composto por informações obtidas em imagens Landsat e mapas pedológicos da EMBRAPA (SOARES et al., 2017).

As imagens Landsat foram utilizadas para verificar as mudanças de uso e ocupação da terra na bacia hidrográfica ao longo do tempo. Imagens de satélite são utilizadas para estimar os valores CN de uma bacia hidrográfica, e inclusive, alguns trabalhos são desenvolvidos para simplificar e adaptar os valores CN das tabelas originais do NRCS, ocorrendo uma redução dos valores $C N$, reduzidos de acordo com o uso e a ocupação da terra identificados em imagens de satélites. $O$ 
valor CN foi obtido a partir da associação entre os usos e a ocupação da terra apresentadas pelas imagens Landsat. O grupo hidrológico do solo foi determinado por meio de informações de solos obtidas na EMBRAPA.

Segundo Soares et al. (2017, p. 6), os valores CN foram simplificados e adaptados, resumindo-se ao uso agricultura, a corpos d'água, à pastagem, às florestas naturais e/ou silvicultura e para áreas urbanas. Foi definida uma curva de permanência para a bacia hidrográfica do rio Ivaí, ou seja, significa a capacidade da bacia hidrográfica em reter as águas superficiais e os dados de vazão (tempo de duração da vazão).

Importante frisar que a forma da curva indica as condições de escoamento da água na bacia hidrográfica, e segundo Destefani (2005) apud Soares et al. (Idem), “[...] quanto mais curvatura possuir a curva, maior é a variabilidade do fluxo, ocasionado por fluxos de vazão rápidos e pouca base de fluxo". A curva de permanência da bacia hidrográfica do rio Ivaí mostra uma grande variação, onde em $10 \%$ do tempo de vazão do gráfico (curva de permanência), houve uma variação de $2.500 \mathrm{~m}^{3} / \mathrm{s}$ para $500 \mathrm{~m} 3 / \mathrm{s}$. Essa curva de permanência da bacia do rio Ivaí apresenta uma curvatura que indica um escoamento superficial muito variável, com baixa contribuição das águas subterrâneas e do lençol freático, o que é evidenciado nos períodos de estiagem com a vazões muito baixas.

A bacia do rio Ivaí foi identificada como possuindo $28 \%$ de sua área pertencente ao grupo hidrológico A (34\% latossolos e $66 \%$ argilossolos), solos com textura arenosa, profundos e bem drenados, $40 \%$ da área foi classificada como do grupo hidrológico B (60\% latossolos, 39\% nitossolos e 1\% argissolos), solos também arenosos com pouca presença de argila, propiciando uma boa infiltração, reduzindo o escoamento superficial (SOARES et al., 2017). O grupo hidrológico $C$ constituiu apenas 3\% (48\% cambissolos, $49 \%$ nitossolos e $4 \%$ neossolos), com maior concentração de argila se comparado aos solos pertencentes ao grupo B e, portanto, reduzindo a infiltração. Em $28 \%$ da área houve predominância de solos do grupo D, com supremacia dos neossolos (99\%), gleissolos e organossolos (1\%) 
que complementaram a área do grupo $D$, solos estes com baixa capacidade de infiltração e que favorecem a formação do escoamento superficial (argilas pesadas e impermeáveis) (SOARES et al., 2017).

Determinando-se os usos e a ocupação da terra e o grupo hidrológico do solo, foram atribuídos valores CN para os pixels da imagem para os períodos analisados na pesquisa, onde a imagem classificada com pixels de tonalidades escuras associa-se a CN baixos e vice-versa. Na parte norte da bacia hidrográfica, detectou-se um aumento dos valores $\mathrm{CN}$ com o avanço da agricultura ao longo do período analisado, ou seja, um aumento do escoamento superficial do ano de 1986 para 2011 devido ao avanço agrícola na região norte da bacia do rio Ivaí. Mais da metade da bacia permanece com os mesmos valores $\mathrm{CN}$ identificados no ano de 1986, se comparados ao ano de 2011. Assim, observa-se que "[...] 22\% dos pixels traduzem o aumento da impermeabilização e 15\% a diminuição da mesma". Atribuiu-se o aumento da impermeabilização ao avanço das áreas urbanas e de uso agrícola, e também aos solos frágeis com argilas que induzem à formação do escoamento superficial. Áreas de pastagens foram urbanizadas, o que resultou no “[...] aumento da curva de escoamento, ou na piora dos valores do CN (SOARES et al., 2017, p.12).

Assim, a curva de escoamento que apresenta o hidrograma torna-se acentuada (fechada) quando há o aumento dos valores CN, ou seja, quando possui solos de grupos hidrológicos do grupo D, ou próximos, ou mesmo, quando há transformação, por exemplo, de áreas vegetação nativa em uso urbano. Uma acentuada curva de escoamento pode indicar uma bacia em que sua vazão tem pouca contribuição do lençol freático e uma alta participação da precipitação efetiva, ou seja, aquela parte da precipitação total que se transforma em escoamento superficial.

A bacia hidrográfica do rio Ivaí apresentou um valor $\mathrm{CN}$ (potencial de escoamento) médio-alto, CN igual a 66 em 1986 e subindo para 68 em 2011. A análise de correlação canônica entre os dados de vazão e o Método SCS-CN 
apresentou-se muito significativa, expressando alta correlação entre as vazões e o Método SCS-CN. Segundo Soares et al. (2017, p.14), os resultados da pesquisa na bacia hidrográfica do rio Ivaí "[...] confirmam a hipótese de que o CN pode ser validado pela vazão, pois de acordo com os resultados, eles não são independentes e estão altamente relacionados [...]".

Um estudo realizado na Índia objetivou estudar o comportamento da precipitação-escoamento superficial em parcelas experimentais de estudo, comparando os valores $\mathrm{CN}$ das tabelas do NEH-4 com aqueles valores $\mathrm{CN}$ derivados de dados de precipitação-escoamento superficial coletados. Posteriormente, otimizaram-se os índices de abstração inicial $(\lambda)$ e a capacidade de armazenamento de água do solo (S) a partir dos dados de precipitação e de escoamento superficial obtidos em 27 parcelas experimentais de estudo no território indiano. Foram avaliadas a performance do emprego do Método SCS-CN com $\lambda=0,20$ e a sensibilidade da variação de $\lambda$ na determinação do escoamento superficial (LAL, M. et al., 2016).

A capacidade de armazenamento de água do solo foi determinada a partir da Equação 15:

$$
S=\left(\left(\{2 \lambda P+(1-\lambda) Q\}-\sqrt{ }\left(\{2 \lambda P+(1-\lambda) Q\}^{\wedge} 2-4(\lambda P)^{\wedge} 2+4 \lambda \wedge 2 Q P\right)\right)\right) / 2 \lambda^{2}
$$

Onde:

$\mathrm{S}=$ Capacidade de armazenamento de água do solo $(\mathrm{mm})$;

$\mathrm{P}=$ Precipitação $(\mathrm{mm})$;

$\mathrm{Q}=$ Escoamento superficial $(\mathrm{mm})$;

$\lambda=$ índice de abstração inicial - relação la/S.

Fonte: Hawkins (1973) apud Lal et al. (2016)

A partir do conhecimento da capacidade de armazenamento de água do solo foram determinados os valores $\mathrm{CN}$, denominados de valores $\mathrm{CN}$-derivados, por meio da Equação 16:

$$
\mathrm{CN}=25400 /(\mathrm{S}+254)
$$

Onde:

$\mathrm{CN}=$ valor $\mathrm{CN}$ (adimensional)

$\mathrm{S}=$ capacidade de armazenamento de água do solo $-\mathrm{mm}$

Fonte: Idem 
Inicialmente, valores CN foram determinados a partir das tabelas do NEH-4, considerando o grupo hidrológico do solo e o uso e ocupação da terra. Posteriormente, foi determinado o valor $\mathrm{CN}$ a partir dos dados de precipitação e de escoamento superficial, com o uso das Equações 15 e 16. A capacidade de armazenamento de água do solo foi determinada a partir da Equação 15, considerando o índice de abstração inicial como $20 \%$ da capacidade de armazenamento de água do solo $(\lambda=0,2)$, e, então, determinados os valores $C N$ por meio da Equação 16. Posteriormente, foram determinados novos valores CN, mas, com outros índices de abstração inicial obtidos por meio da ferramenta Solver do Excel (método dos mínimos quadrados), utilizando os dados de precipitação e de escoamento superficial coletados em locus. Portanto, foram determinados valores $\mathrm{CN}$ com valores $\lambda$ otimizados e com valores $\lambda=0,2$

A condição antecedente de umidade (AMC) foi determinada de acordo com a precipitação dos 5 dias anteriores ao evento pluviométrico analisado. Foram analisados eventos pluviométricos (precipitação e escoamento superficial) naturais que vão desde volumes de $6 \mathrm{~mm}$ a $75 \mathrm{~mm}$ em parcelas 'fixas' - três estágios de desenvolvimento da cultura - em diferentes declividades, usos da terra e grupo hidrológico do solo (LAL, M. et al., 2016).

Obtiveram-se valores CN para cada evento analisado nas parcelas individuais usando as Equações 15 e $16 \operatorname{com} \lambda=0,2$, e comparados com valores $C N$ conseguidos com outros valores de $\lambda$ a partir do emprego do método dos mínimos quadrados. Conforme os autores, os diferentes usos da terra (cana-de açúcar; milho; feijão e área em pousio) analisados não mostraram diferenças significativas nos valores $\mathrm{CN}$, com exceção do uso da cana-de-açúcar que apresentou maiores valores $\mathrm{CN}$ que os usos feijão e área em pousio. As declividades analisadas (5\%; 3\% e 1\%) não apresentaram efeito sobre os valores $\mathrm{CN}$ e foram estatisticamente insignificantes.

De acordo com Lal et al. (2016, p. 9), os valores CN da pesquisa foram influenciados pela capacidade de infiltração do solo, porque os grupos hidrológicos do solo analisados apresentaram diferenças estatisticamente significativas. O valor 
de "S" e de " $\lambda$ " foram obtidos com o emprego do método dos mínimos quadrados a partir da utilização dos dados coletados de precipitação e de escoamento superficial. O método dos mínimos quadrados foi aplicado aos dados naturais e aos dados ordenados em pares de precipitação e de escoamento superficial (P-Q) - ordenados do maior para o menor (ordered data) - ou seja, os pares de precipitação e de escoamento superficial não foram necessariamente os dados ocorridos naturalmente. Os dados naturais apresentaram valores CN de 64.73 a 90.33, e para os dados ordenados, de 67.47 a 90.59 . Conclui-se que a capacidade de infiltração do solo "[...] is the main explanatory variable for runoff production in the study plots". Houve uma relação inversa entre $\mathrm{CN}$ e a capacidade de infiltração do solo, ou seja, quanto maior CN menor a capacidade de infiltração.

O valor $\mathrm{CN}$ obtido nas tabelas do NEH-4 foram comparados com os valores obtidos a partir de dados naturais (e ordenados) de precipitação e do escoamento superficial obtidos nas parcelas experimentais. Os valores CN obtidos no NEH-4 variaram de 58 a 88. Com o método dos mínimos quadrados para os dados naturais os valores CN variaram de 64,73 a 90,33 , e para os dados ordenados de 67,47 para 90,59 . Em suma, os valores $C N$ com dados 'P-Q' foram maiores que os valores $\mathrm{CN}$ do NEH-4.

Segundo Lal et al. (2016), há um melhor desempenho do Método SCS-CN quando analisados eventos 'P-Q' elevados, ou CN elevados. Os valores CN ordenados são maiores do que os valores CN naturais, como demonstrados por outros autores. Indicam a utilização do valor CN ordenado ao invés do CN obtido nas tabelas do NEH-4 para áreas com características físicas semelhantes às parcelas experimentais. Gundalia e Dholakia (2014) avaliaram os procedimentos para a determinação de valores CN mensalmente para a previsão do volume de escoamento em uma bacia hidrográfica na Índia (bacia hidrográfica de Ozat), estado de Gujarat. Resultados indicaram haver melhoras na aplicação do Método SCS-CN com a utilização de valores CN mensais para a bacia hidrográfica analisada. Também, os valores CN aumentam com a variação do índice de abstração inicial 
de 0,05 para 0,2, mostrando a importância na determinação da lambda, e que os métodos analisados na pesquisa apresentaram melhor desempenho na determinação do escoamento superficial $\operatorname{com} \lambda=0,05$ para a bacia hidrográfica de Ozat.

Avaliou-se e comparou o escoamento superficial obtido através da metodologia SCS com eventos de chuva e vazão observados na área de estudo em Minas Gerais (Brasil). O escoamento superficial obtido pelo método SCS considerou os valores CN contidos nas tabelas do NRCS, e posteriormente, foi determinado o escoamento superficial calibrados a partir da altura da chuva, método introduzido por Hawkins (1993). Os resultados mostraram que o método SCS tende a superestimar o escoamento superficial e as vazões de pico, e o modelo ajustado pela altura da chuva apresentou com menor erro percentual se comparados aos eventos monitorados (CUNHA et al., 2015).

O valor $\mathrm{CN}$ foi determinado com o uso de um simulador de chuva que forneceu dados de precipitação e de escoamento superficial com a utilização de parcelas experimentais em diversas áreas localizadas no estado de lowa (EUA). A partir desses dados, foram definidas a abstração inicial e a capacidade de armazenamento de água do solo. Prosseguindo, foram determinados novos valores CN para os usos e a ocupação da terra analisados na pesquisa, identificando os efeitos do tipo de solo, da condição de umidade do solo, das práticas agrícolas e da cobertura no valor CN. Objetivou-se, também, investigar os efeitos da intensidade da precipitação no escoamento superficial e no valor $\mathrm{CN}$ (ELHAKEEM; PAPANICOLAOU, 2009). Definiram-se os locais para as realizações das simulações de chuva em parcelas experimentais em solos com texturas diferentes representando os quatro grupos hidrológicos dos solos definidos pelo NRCS. Concluem que os simuladores de chuva são instrumentos confiáveis para estimar no local o valor $\mathrm{CN}$, devido ao controle da intensidade da chuva durante o experimento. Também, porque os simuladores de chuva eliminam a necessidade de uma chuva natural (ELHAKEEM; PAPANICOLAOU, 2009). 
O valor $\mathrm{CN}$ estimado para o verão foi próximo ao valor $\mathrm{CN}$ tabelado pelo NRCS definidos para a pesquisa. Entretanto, o valor CN do outono foi menor do que o CN tabelado, fato atribuído à cobertura de resíduos da colheita. De acordo com a pesquisa, a intensidade da chuva, as práticas agrícolas (plantio direto; rotação de cultura e cultivo convencional) e do tipo de cultura analisada (milho; soja) foram irrelevantes se comparados aos fatores umidade do solo e cobertura de resíduos (palhada). As equações do Método CN foram modificadas para considerar a umidade e a cobertura de palhada para melhor estimativa do escoamento superficial para os usos da terra analisados (ELHAKEEM; PAPANICOLAOU, 2009). De acordo com Elhakeem e Papanicolaou (2009), os valores CN obtidos nas diferentes parcelas e campos podem ser utilizados ou mesmo integrado a outros valores $\mathrm{CN}$ para obter um valor $\mathrm{CN}$ representativo para bacias hidrográficas com mesmas características físicas e de uso e ocupação da terra. No entanto, os dados necessitam ser confirmados a partir de dados em bacias hidrográficas de mesma característica e que disponham de dados hidrológicos de longo prazo.

Valores $\mathrm{CN}$ foram determinados por meio de três diferentes métodos, o método NEH-4 - que utiliza a Equação Geral do Método CN com a abstração como $20 \%$ da capacidade de armazenamento de água do solo - o qual, mediante dados medidos de precipitação e escoamento superficial, determina a capacidade de armazenamento de água do solo e, posteriormente, determina o valor CN (denominado de $\mathrm{CN}_{\mathrm{m}}$ ). Também utilizou-se o Método dos Mínimos Quadrados para obter o melhor ajuste dos dados de precipitação e de escoamento superficial para obter um valor de $\mathrm{S}$ e de $\lambda$ para cada parcela experimentada, e, posteriormente, determina-se o valor $\mathrm{CN}$ para os dados naturais $\left(\mathrm{CN}_{\mathrm{LSMn}}\right)$ e ordenados ( $\left.\mathrm{CN}_{\mathrm{LSMO}}\right)$. Por fim, foram determinados os valores $\mathrm{CN}$ pelas tabelas NEH-4 ( $\mathrm{CN}_{\mathrm{HT}}$ ). Os valores $\mathrm{CN}_{\mathrm{m}}$ foram maiores do que os valores $\mathrm{CN}_{\mathrm{HT}}$, e a maior discrepância está em valores $\mathrm{CN}_{\mathrm{HT}}$ menores do que 75 , ou seja, os valores $\mathrm{CN}$ determinados por meio de dados de precipitação e de escoamento superficial são maiores do que os valores $\mathrm{CN}$ 
encontrados nas tabelas e nos gráficos do NRCS. Em sua maioria, os valores $\mathrm{CN}_{\mathrm{m}}$ foram maiores do que os valores CN $\mathrm{N}_{\mathrm{LSM}}$ obtidos com o Método dos Mínimos Quadrados (LAL, M.; MISHRA; PANDEY, A., 2015).

De acordo com Lal, Mishra e Pandey (2015), os valores CN aumentam com o incremento da declividade nas parcelas, e observou-se a interferência da rampa de declividade nos valores CN para o mesmo tipo de solo e usos e ocupação da terra. O escoamento superficial foi determinado através do Método $\mathrm{CN}$ com os valores $\mathrm{CN}$ obtidos das tabelas do NEH-4, e este escoamento superficial foi comparado com o escoamento superficial observado nas parcelas experimentais. Os resultados indicaram que o Método $\mathrm{CN}$ subestima o escoamento superficial nos grandes eventos de escoamento superficial observados, e que superestima o escoamento superficial para pequenos eventos de escoamento superficial. Para Garg et al. (2013) e Mishra et al. (2014), a declividade afeta significativamente o escoamento superficial. Shi et al. (2009) ajustaram os índices de abstração inicial por meio de dados de precipitação e de escoamento superficial, e verificou-se que o escoamento superficial determinado com o índice original e com o índice modificado apresentou diferenças. O escoamento superficial estimado com o índice de abstração inicial modificado aproximou-se melhor do escoamento superficial medido nas bacias hidrográficas. Concluíram que o Método CN padrão subestima o escoamento superficial para grandes eventos de escoamento superficial. Os valores $\mathrm{CN}$ derivados de dados de precipitação e de escoamento superficial coletados nas parcelas experimentais foram diferentes dos valores $\mathrm{CN}$ obtidos nas tabelas do NEH-4. Valores CN ajustados com a declividade das parcelas experimentais melhor se aproximaram ao escoamento superficial observado do que o escoamento superficial obtido a partir de valores $\mathrm{CN}$ selecionados nas tabelas do NEH-4.

Valores CN foram determinados a partir das tabelas do NEH-4, levando em consideração as características físicas das bacias hidrográficas e, também, mediante dados de precipitação e de escoamento superficial, utilizando-se de 
fórmulas que consideram a abstração inicial como $20 \%$ da capacidade de armazenamento de água e de fórmulas que consideram a abstração inicial como $5 \%$ da capacidade de armazenamento de água do solo. O modelo que considera a abstração inicial como 5\% da capacidade de armazenamento de água do solo apresentou melhor desempenho do que o modelo que considera a abstração inicial como $20 \%$ do armazenamento de água do solo. Um dos modelos propostos na pesquisa considerou a abstração inicial como $2 \%$ da precipitação incidente, e este modelo foi um dos melhores modelos analisados quando se comparou o escoamento superficial estimado com o escoamento superficial observado (dados coletados), ou seja, la=0,02·P ('P' igual à precipitação) com melhor desempenho do que se comparado aos modelos que considera a abstração inicial como la=0,2.S ou la $=0,05 \cdot S$ (AJMAL et al., 2015).

De acordo com Teegavarapu e Chinatalapudi (2018), em um estudo de caso realizado no estado da Flórida (EUA), relacionou-se a umidade do solo ao nível do lençol freático superficial e, a partir de então, obteve-se um valor CN ajustado ao nível do nível do lençol freático, o qual, por sua vez, interferiu na umidade do solo. Concluíram que as condições do nível do lençol freático influenciam significativamente no escoamento superficial, e que o aumento dos valores CN são devidos à redução da capacidade de retenção de umidade pelo solo (TEEGAVARAPU; CHINATALAPUDI, 2018).

Foi desenvolvida uma pesquisa no Cerrado brasileiro para a obtenção de valores CN na vegetação cerrado e em culturas encontradas na região, quantificando a chuva e o escoamento superficial em parcelas experimentais a fim de derivar valores $\mathrm{CN}$ a partir dos dados e utilizando cinco métodos estatísticos. Os valores CN obtidos por meio das tabelas do NRCS foram apropriados para determinar o escoamento superficial no solo nu, na cultura da soja e na cana-deaçúcar. Contudo, valores $\mathrm{CN}$ derivados a partir de dados coletados melhor estimaram o escoamento superficial se comparados aos valores $\mathrm{CN}$ tabelados a partir do NRCS. De acordo com a pesquisa, o método CN não se apresentou 
adequado para estimar o escoamento superficial para o Cerrado, para o solo exposto, na pastagem e no milheto (OLIVEIRA et al., 2016). A seguir, serão abordados alguns fatores principais considerados para a determinação do valor $\mathrm{CN}$, como o uso da terra e as classes de tratamento do solo, a condição hidrológica da área de bacia hidrográfica e o grupo hidrológico do solo.

\subsection{1 Índice de abstração inicial}

Como mencionado, a abstração inicial constitui a parcela da precipitação incidente desde o início da chuva até o instante em que se inicia o escoamento superficial, que representa a parcela da precipitação total evaporada diretamente para a atmosfera durante e após os eventos pluviométricos, pela água interceptada pela vegetação, pelo armazenamento superficial e, também, a infiltração inicial, instantes antes do início do processo de escoamento superficial.

No processo de desenvolvimento do Método CN, várias proposições foram criadas para simular a relação chuva-escoamento superficial, e as primeiras versões não enquadravam a abstração inicial. O NRCS definiu a la conforme a capacidade de armazenamento de água do solo.

O Natural Resources Conservation Service (NRCS) estabeleceu a relação entre a abstração inicial e a capacidade de armazenamento do solo, sendo a abstração inicial representada por $20 \%$ da capacidade de armazenamento de água pelo solo (la/S) (HAWKINS, R. H., 1993; PONCE; HAWKINS, R. H., 1996; TUCCI, 2009; USDA-NRCS, 2002; WOODWARD, D. E. et al., 2003).

Este índice de $1 \mathrm{a}=0,2 \cdot \mathrm{S}$ (ou seja, $20 \%$ da capacidade de armazenamento de água do solo) sofreu grandes variações, e $20 \%$ representam a mediana dos dados. As pesquisas indicam uma grande variação que vai de $1 \%$ a $99 \%$ de Ia/S (IIANG, 2001; USDA-NRCS, 2004a). Este índice de la é investigado em diversas regiões do mundo, como no Brasil, na Europa, na China, entre outros países e continentes. 
O método frequentemente utilizado em diversas pesquisas para a determinação dos índices de la denomina-se 'análise de evento', que consiste em monitorar os eventos pluviométricos, conhecendo-se o hietograma e o hidrograma da bacia hidrográfica. A análise de evento inicia-se com a observação dos eventos pluviométricos, e o volume de precipitação, desde o início do evento até o instante que se inicia o escoamento superficial direto, constituí a la. Com esse método, cada evento pluviométrico forneceu uma relação la/S (denominada de ' $\lambda$ '), e os valores médios dessa relação são usados para caracterizar a bacia hidrográfica. Cabe salientar que o método análise de evento foi originalmente utilizado pelo NRCS para estipular os índices de Ia=0,2·S (BALTAS; DERVOS; MIMIKOU, 2007; HAWKINS, R. H.; KHOJEINI, 2000; WOODWARD, D. E. et al., 2003).

Críticas são apresentadas ao fato de o NRCS apresentar somente um gráfico (Figura 1) com os dados utilizados para o estabelecimento do índice de abstração inicial (la $=0,2 \cdot S)$ oficial do método $\mathrm{CN}$, relacionando a abstração inicial à capacidade de armazenamento de água do solo. Neste sentido, no artigo apresentado por Hawkins e Khojeini (2000), definiram-se os índices de abstração inicial a partir de dados de precipitação e de escoamento superficial de 86 bacias hidrográficas, principalmente bacias agrícolas dos territórios dos Estados Unidos. Os métodos utilizados para determinar os índices de abstração inicial foram a análise de evento e o método dos mínimos quadrados.

Utilizaram dados de 2.163 estações e 5.501 eventos de precipitaçãoescoamento superficial de diversos institutos de pesquisas, de universidades e/ou de pesquisadores. Os eventos pluviométricos selecionados foram superiores ou iguais a uma polegada $(2,54 \mathrm{~cm})$, e em bacias hidrográficas onde observou-se, no mínimo, 20 eventos desta mesma natureza.

O método análise de evento fornece os índices de la a partir dos dados de escoamento superficial e da precipitação, sendo a la a parcela da chuva antes do início do escoamento superficial, ou quando o hidrograma observado começou a elevar-se. O volume de precipitação, os dados de la e o escoamento superficial são 
utilizados para resolver a Equação 8, obtendo, assim, os dados da capacidade de armazenamento de água do solo. Determinando-se a abstração inicial e a capacidade de armazenamento de água do solo, tem-se os índices de abstração inicial (BALTAS; DERVOS; MIMIKOU, 2007; HAWKINS, R. H.; KHOJEINI, 2000; JIANG, 2001; WOODWARD, D. E. et al., 2003).

Conforme Hawkins e Khojeini (2000), por meio do método análise de evento cada evento pluviométrico (dados de precipitação e de escoamento superficial) apresentou uma ' $\lambda$ ' e os dados medianos foram utilizados para classificar a bacia hidrográfica. Outro método utilizado foi o dos mínimos quadrados obtidos a partir da análise dos dados coletados de precipitação e de escoamento superficial, ajustando-se os valores de " $\lambda$ " e "S" com a utilização da Equação 17:

$$
Q=\frac{\left((P-\lambda S)^{2}\right)}{((P+(1-\lambda) S))}
$$

Em que:

$\mathrm{Q}=$ escoamento superficial

$\mathrm{P}=$ precipitação

$\mathrm{S}=$ capacidade de armazenamento de água pelo solo

$\lambda=$ índice de abstração inicial

Fonte: Hawkins e Khojeini (2000, p.30)

Assim, cada bacia hidrográfica adquiriu um valor ' $\lambda$ ' e ' $S$ '. Os dados forneceram um gráfico de frequência acumulada da média de la/S, onde os valores encontrados de la/S foram predominantemente menores dos que os 0,20 proposto pelo SCS atual NRCS. Das 86 bacias hidrográficas analisadas, apenas 5 apresentaram valores maiores que 0,20, e afirmam que 0,05 apresenta-se como um índice mais apropriado para a relação la/S. Em bacias hidrográficas com uso da terra floresta, a média de la/S para os dados naturais foi de 0,0584 e a mediana zero (HAWKINS, R. H.; KHOJEINI, 2000).

Prosseguindo com a discussão, Hawkins e Khojeini (2000) trazem que um dos maiores índices médios de la/S foram obtidos nas bacias hidrográficas agrícolas localizadas no leste e no meio oeste estadunidense, $\operatorname{com} \lambda=0,0755$, mas, mesmo assim, inferior a $\lambda=0,2$. Nos dados naturais fornecidos por Hewlett et al. (1984) 
citado por Hawkins e Khojeini (2000), a partir de 17 bacias hidrográficas florestadas, a média de la/S foi de 0,0584 e a mediana zero. As análises dos dados ajustados apresentaram uma média de 0,1143 e uma mediana de 0,0215, superior aos dados naturais.

Nos dados fornecidos pela Jornada, os dados naturais apresentaram uma média de 0,0122 e a mediana foi zero. Nos dados ajustados, a média foi de 0,1699 e a mediana 0,0037, superior à apresentada pelos dados naturais e inferior aos 0,2 do SCS. Os dados de precipitação e de escoamento superficial das bacias hidrográficas agrícolas fornecidos pelo Departamento de Agricultura dos EUA apresentaram, para os dados naturais, uma média de 0,0755 e a mediana foi zero. Os dados ajustados apresentaram uma média de 0,1572 e a mediana 0,0966. Somente as médias dos dados ajustados apresentaram valores próximos aos 0,2, sendo a mediana próxima a 0,05. As médias dos dados naturais ficaram próximos a 0,05 e distante dos 0,2 (HAWKINS, R. H.; KHOJEINI, 2000). O estudo indicou que $\mathrm{la}=0,05 \cdot \mathrm{S}$ deve ser um índice mais apropriado para diversas áreas analisadas na pesquisa.

A partir de um estudo conduzido em uma bacia hidrográfica experimental na província de Attica (Grécia), com área de $15 \mathrm{~km}^{2}$, com diversos uso da terra e formações geológicas com altitudes que variam de 146 m a 950 m e declividade média de $21 \%$, foram determinados os índices de abstração inicial por meio da análise de dados de precipitação e de escoamento superficial. A vegetação predominante na bacia é de pastagens, com uma pequena área habitada na parte sul da bacia hidrográfica. A bacia hidrográfica foi dividida devido às suas características geológicas na parte norte e na parte sul, constituída em sua totalidade de xisto (60\% da área), 23\% formada por conglomerados, $9 \%$ calcário (marga) e $8 \%$ de mármores. No norte da bacia, há o predomínio de xistos intercalados com mármores apresentando fraturas e com a camada superior erodida (BALTAS; DERVOS; MIMIKOU, 2007). 
Salienta-se que um aquífero cárstico alimenta escoamento de base da bacia hidrográfica que é perene. Na porção sul da bacia hidrográfica, verifica-se a presença de conglomerados com frações variáveis de argila e de areia (ou seja, variável capacidade de infiltração) e baixos percentuais de formações de calcário impermeáveis. As coletas dos dados de escoamento superficial foram realizadas a partir de duas estações hidrométricas e uma rede de pluviômetros instalados em locais de diferentes altitudes, com gravações de dados de 10 em 10 minutos, os quais forneceram os dados de precipitação pluviométrica.

Uma das estações hidrométricas localiza-se na foz da bacia e a outra na saída da bacia do norte. Analisaram-se dezoito eventos pluviométricos de diversas intensidades. A separação do escoamento superficial direto do escoamento superficial de base procedeu-se com a observação dos pontos de inflexão do hidrograma, indicando o início e o fim do escoamento superficial direto. Finalmente, definiu-se a abstração inicial como parte da precipitação desde o início do evento pluviométrico até o instante em que se inicia o escoamento superficial direto. O parâmetro capacidade de armazenamento de água do solo obteve-se com o emprego da equação geral do Método $\mathrm{CN}$, e dividindo-se a abstração inicial por 'S' foram obtidos os índices de abstração inicial para cada evento pluviométrico analisado (BALTAS; DERVOS; MIMIKOU, 2007).

A média do índice la para as bacias hidrográficas (bacia hidrográfica norte e bacia hidrográfica sul) analisadas foi de 0,014, com um máximo de 0,037 e um mínimo de 0,004, predominando valores de 0,01, e os autores afirmam que esses dados não estão relacionados com a intensidade da precipitação. A sub-bacia hidrográfica do norte apresentou uma oscilação na la de 0,014 a 0,054, com média de 0,037 , superior à média aritmética de toda a bacia hidrográfica, provavelmente devido à maior capacidade geológica de reter chuva (maior capacidade de infiltração) e a menor antropização se comparada em relação à bacia hidrográfica do sul. Como mencionado, na bacia hidrográfica do sul encontram-se áreas residenciais, estradas e formações rochosas impermeáveis o que reduz a 
capacidade de abstração inicial da chuva (BALTAS; DERVOS; MIMIKOU, 2007). A média de la de toda a bacia hidrográfica é menor do que na sub-bacia hidrográfica do norte, evidenciando a maior capacidade de retenção de água devido às diferenças no uso e ocupação da terra, nas características geológicas e ao fato de a bacia hidrográfica do sul localizar-se próximo ao exutório de toda a bacia hidrográfica, levando essa parte a ter maior escoamento superficial e menor capacidade de retenção de água.

De acordo com Baltas, Dervos e Mimikou (2007), a definição da condição antecedente de escoamento ARC - II ou III para a bacia hidrográfica analisada, levou à redução nos índices de abstração inicial, pois, correlaciona-se à capacidade de armazenamento de água do solo. Ressalta-se que a abstração inicial depende da condição antecedente de escoamento, que, por sua vez, depende da condição antecedente de umidade do solo. Também, a interceptação vegetal das áreas de pastagens da bacia hidrográfica do norte contribui com os maiores índices de la e reduz o escoamento superficial.

Uma pesquisa objetivando conhecer os índices de la e a capacidade de armazenamento de água do solo foi realizada em uma bacia hidrográfica localizada no sudeste do Arizona (EUA) com uma área total de $148 \mathrm{~km}^{2}$, a uma altitude variando de 1271 m a 1929 m e uma precipitação anual de 324 mm. A vegetação predominante na bacia hidrográfica constitui-se de arbustos com gramíneas. Solos arenosos e bem drenados representam mais de 70\% da área (YUAN et al., 2014).

Posteriormente, determinou-se o escoamento superficial com o índice de la estipulado pelo NRCS e a la otimizada na pesquisa. Foi realizada uma análise de sensibilidade nos dados que avaliou o efeito de alterações nos índices de abstração inicial na estimativa do escoamento superficial. O índice de la foi sendo reduzido progressivamente e as mudanças dos índices de la foram avaliadas.

De acordo com Yuan et al. (2014), a estimativa do escoamento superficial pode ser sensível às alterações dos índices de abstração inicial, especialmente para eventos pluviométricos de baixa intensidade e para bacias hidrográficas de solos 
profundos, textura grosseira e com elevada porosidade, características de regiões semiáridas; e os autores afirmam que para estas bacias hidrográficas do Arizona (região semiárida do oeste norte-americano), os índices de abstração inicial estão associados à área do canal de drenagem da bacia, ao tipo de solo e à cobertura da bacia. Assim, para precipitação de $25,4 \mathrm{~mm}$, a sensibilidade da abstração inicial aumentou com a redução do valor CN. A bacia hidrográfica analisada na pesquisa localiza-se em uma região semiárida e foi classificada com baixos valores $C N$, apresentando, portanto, elevada sensibilidade na estimativa do escoamento superficial em função das variações das taxas de abstração inicial.

Concluem que quanto maior for a área do canal de drenagem e mais fino for o solo da bacia hidrográfica, menores serão os índices de la. Assim, indicam não ser eficiente a taxa de $\lambda=0,2$ para as bacias hidrográficas analisadas que localizamse no sudeste do Arizona, região de clima semiárido, e afirmam que a estimativa do escoamento superficial pode ser prejudicada pelos valores da abstração inicial, principalmente em eventos de baixa intensidade e volume, e em bacias hidrográficas que possuem solos profundos e porosos, características de climas semiáridos.

Salientam que os valores ideais para os índices de la para bacias hidrográficas localizadas no semiárido podem variar de 0,01 a 0,53. Ainda nesse sentido, afirmam que quanto maior a área do canal de drenagem da bacia hidrográfica, maior será o potencial de armazenamento de água no solo, e quanto mais grosseira a textura maior será a 'la' (YUAN et al., 2014). A média dos índices de abstração inicial das bacias hidrográficas analisados foi de $\lambda=0,12$.

Uma pesquisa objetivando determinar o tempo e o índice (lâmina de abstração inicial) de abstração inicial foi conduzida em uma microbacia hidrográfica de escoamento temporário nas proximidades da cidade de Lavras (MG). O clima da região apresenta invernos secos e as chuvas concentradas nos meses de novembro a março. A microbacia possui uma área de 1,5 ha, sendo 50\% constituída por eucaliptos, aproximadamente $40 \%$ de braquiária e 10\% de várzea. 
A declividade média da microbacia é de $15 \%$, e os solos são formados por cambissolo (80\%), Glei Pouco Húmico (10\%) e Argissolo (10\%).

A abstração inicial foi obtida pelo método 'análise de evento', onde foram analisados o hietograma e o hidrograma de 25 eventos dos anos 2002 a 2003. A precipitação foi obtida em uma estação climatológica que registrou eventos de 10 em 10 minutos. Já o escoamento superficial foi obtido a partir de um linígrafo automático, com registros também a cada 10 minutos, instalado em uma calha Parshall com a calibração da curva-chave. A umidade do solo foi obtida a partir da instalação de sensores (ou blocos) de resistência elétrica e de tensiômetros.

A média do índice de abstração inicial foi de 0,0155, e apresentou uma grande variabilidade do índice de abstração inicial (0 a 0,081), concluindo não ser eficiente estipular a abstração inicial apenas na capacidade de armazenamento de água do solo. Conclui-se que os índices de abstração inicial estão altamente associados ao comportamento da precipitação, e se o escoamento superficial (precipitação efetiva) "[...] ocorrer logo no início do evento, sua abstração inicial será zero, independentemente da umidade antecedente (MELLO et al., 2003, p. 497)". Observou-se que o tempo de abstração inicial possui significância com a variável 'tempo necessário para se atingir a precipitação máxima', e o tempo de abstração inicial possui influência das condições de umidade antecedente, pois

[...] quanto menor a umidade antecedente (maior a capacidade de armazenamento da bacia hidrográfica), menor a tendência de escoamento e mais tempo será necessário para se atingir o início do mesmo. (Idem, p. 498).

Os dados da relação abstração inicial e a capacidade de armazenamento da bacia hidrográfica mostraram grande variabilidade ao longo do período de estudo no sul de Minas Gerais, onde a razão la/S apresentou um valor médio de 0,0155, ou seja, $\lambda=0,0155 \cdot S$ (1,55\% da capacidade máxima de armazenamento de água da bacia hidrográfica), com valores mínimos de zero e máximo de 0,081. Assim, essa [...]: 
[...] grande variabilidade sugere que, para obtenção de Ai [abstração inicial], não se deve considerar apenas o armazenamento potencial, mas é imprescindível que se verifique a influência de variáveis hidrológicas no processo, especialmente a precipitação. (Ibidem, p.498).

Salienta-se que se o Método CN for aplicado à bacia hidrográfica analisada (microbacia de escoamento efêmero), os resultados são dúbios, necessitando de estudos do seu “[...] comportamento hidrológico, em especial [...] eventos de precipitação". Sugerem que há influência da umidade antecedente média a 20 cm no "[...] comportamento da lâmina e do tempo relativo à abstração inicial" (MELLO et al., 2003, p.499). Concluem que a abstração inicial não deve ser calculada apenas com base na capacidade de armazenamento de água do solo, considerando-se, também, outros parâmetros hidrológicos.

De acordo com Elhakeem e Papanicolaou (2009), os resultados de uma pesquisa no estado norte-americano de lowa em parcelas experimentais das culturas do milho e da soja mostraram não haver uma relação linear entre a capacidade máxima de armazenamento de água do solo e a abstração inicial, sendo influenciado pela cobertura de palhada (resíduo da colheita da cultura).

Para Ponce e Hawkins (1996), a quantificação da abstração inicial pode constituir-se em uma complexa questão, todavia, necessitando de investigação e do seu conhecimento, devendo ser visto como um parâmetro regional proporcionado pelas condições geológicas e climáticas. A quantificação e o refinamento dos dados de abstração inicial é possível, contudo, ainda são pouco conhecidos os processos de interceptação, a infiltração superficial, fatores que interferem nos índices de la em cada uso e ocupação da terra, e também, para os tipos de solo (WOODWARD, D.E. et al., 2002).

Os cálculos de escoamento superficial com a utilização do Método CN, adotando seus parâmetros originais, podem incorrer em erros, subestimando-os ou superestimando-os, podendo gerar graves problemas para o ser humano e para o meio ambiente. Lal, Mishra e Pandey (2015) otimizaram os índices de abstração inicial por meio de dados de precipitação e de escoamento superficial coletados, e 
os resultados indicaram que o índice de abstração inicial como $20 \%$ da capacidade de armazenamento de água do solo é elevado $(\lambda=0,2)$, sendo, em sua pesquisa, apresentado índices com mediana de zero e média de $\lambda=0,034$.

\section{CONCLUSÃO}

O método Curve Number apresenta-se como uma ferramenta no auxílio de gestores e de pesquisadores no conhecimento do escoamento superficial e da capacidade de armazenamento de água do solo em pequenas bacias hidrográficas. Para a estimativa do escoamento superficial pelo Método SCS-CN são requeridos dados de fácil obtenção, como dados de precipitação e de uso e ocupação da terra. O método constitui-se em uma poderosa ferramenta na estimação do escoamento superficial e a capacidade de armazenamento de água da bacia hidrográfica, com objetividade e facilidade de aplicação.

As vantagens de utilização do Método $\mathrm{CN}$ consiste pelo fato da mesma ser uma metodologia de simples aplicação para determinar o escoamento superficial e a capacidade de armazenamento de água pelo solo utilizando-se de poucos dados, como o volume de precipitação e o valor CN que é determinado a partir da definição do grupo hidrológico do solo, do uso e ocupação da terra, da condição hidrológica e da condição antecedente de umidade.

Todavia, críticas são tecidas a metodologia devido este parâmetro, o valor $\mathrm{CN}$, ser um dado numérico que representa o tipo de solo, a condição hidrológica e o uso e ocupação da terra. Neste sentido, os valores CN's podem variar para as diferentes condições edafoclimáticas existentes, necessitando de cautela em sua aplicação. Os parâmetros utilizados pela metodologia foram estipulados a partir de dados de solos, uso e ocupação da terra, condição da superfície e a condição antecedente de umidade de algumas regiões dos EUA, principalmente, do meiooeste americano, recomendando-se cautela em sua utilização fora desses limites. 
Os parâmetros do Método SCS-CN são questionados e pesquisas são necessárias para a determinação do valor CN e da abstração inicial, obtendo, assim, uma melhor estimativa do escoamento superficial e da capacidade de armazenamento de água do solo. No entanto, se ignorado isso, devido aos seus parâmetros serem desenvolvidos em condições edafoclimáticas específicas, os resultados em algumas condições climáticas, geológicas e de solos podem ser questionados, pois distorcem a realidade.

Também são tecidas críticas ao fato de o método não incorporar o tempo em sua equação, determinando o escoamento superficial para um único evento de precipitação, sendo comum a utilização da precipitação total diária. Se o intervalo de chuva exceder em horas, novos valores $\mathrm{CN}$ devem ser estipulados, sempre considerando a alteração da condição antecedente de umidade (WOODWARD, D.E. et al., 2002). O fato de a metodologia também não incorporar dados de declividade em suas equações também é alvo de questionamentos.

A abstração inicial, que representa $20 \%$ da capacidade de armazenamento de água pelo solo, também é alvo de pesquisas, e os resultados apresentam a la $=0,2 \cdot S$ muito elevada ou mesmo variar em função das condições edafoclimáticas e no tempo. Alguns autores reforçam o índice de 5\% para a la ser mais eficaz no emprego da metodologia para uma série de condições geológicas e climáticas. Neste caso, a $l a=0,2 \cdot 5$ pode subestimar o escoamento superficial, podendo gerar consequências nefastas ao meio ambiente e para o próprio homem.

Pesquisas são desenvolvidas com o intuito de melhorar a precisão dos valores CN contidos pelas tabelas do NRCS, sugerindo novos valores CN para regiões específicas. Sugerem a transformação do parâmetro $\mathrm{CN}$ em uma variável contínua ao invés de uma variável discreta, aumentando a precisão do método (VILLARÁN SAN JUAN, DE, 2006). Os dados necessários para estimar o valor CN podem ser obtidos por meio dos Sistemas de Informações Geográficos (SIG's), como da utilização de imagens de satélites para conhecimento do uso e ocupação 
da terra, e por conseguinte, os valores CN's de uma bacia hidrográfica (FELIZARDO, 2016; PAULINO, 2014; POMPERMAYER, 2013).

\section{REFERÊNCIAS}

AJMAL, M. et al. Investigation of SCS-CN and its inspired modified models for runoff estimation in South Korean watersheds. Journal of Hydro-Environment Research, 2015. v. 9, p. 592-603. Disponível em: https://www.sciencedirect.com/science/article/abs/pii/S157064431500012X?via\%3Dihub. Acesso em: 26 nov. 2018.

AJMAL, M; KIM, T. Quantifying Excess Stormwater Using SCS-CN-Based Rainfall Runoff Models and Different Curve Number Determination Methods. USA: Journal of Irrigation and Drainage Engineering, 2015. v. 141, n. 3, p. 363-370. Disponível em: https://ascelibrary.org/doi/pdf/10.1061/\%28ASCE\%29IR.1943-4774.0000805. Acesso em: 13 nov. 2018.

ALI, S.; GHOSH, N. C.; SINGH, R. Rainfall-runoff simulation using a normalized antecedent precipitation index. Hydrological Sciences Journal, 2010. v. 55, n. 2, p. 266-274. Disponível em: http://www.tandfonline.com/doi/abs/10.1080/02626660903546175. Acesso em: 25 jun. 2019.

AUERSWALD, K.; HAIDER, J. Runoff Curve Numbers for small grain under german cropping conditions. Journal of Environmental Management, 1996. v. 47, p. 223-228. Disponível em: http://linkinghub.elsevier.com/retrieve/pii/S0301479796900481. Acesso em: 2 out. 2018.

BALTAS, E. A.; DERVOS, N. A.; MIMIKOU, M. A. Technical Note: Determination of the SCS initial abstraction ratio in an experimental watershed in Greece. Hydrol. Earth Syst. Sci, 2007. v. 11, p. 1825-1829. Disponível em: https://www.hydrol-earth-syst-sci.net/11/1825/2007/hess-111825-2007.pdf. Acesso em: $1^{\circ}$ out. 2018.

BANASIK, K. et al. Curve Number estimation for a small urban catchment from recorded rainfallrunoff events. Zabrze, Polônia: Archives of Environmental Protection, 2014. v. 40, n. 3, April 2016, p. 75-86. Disponível em: https://www.degruyter.com/downloadpdf/j/aep.2014.40.issue3/aep-2014-0032/aep-2014-0032.pdf. Acesso em: $1^{\circ}$ out. 2018.

BANASIK, K.; WOODWARD, D. Empirical determination of runoff Curve Number for a small agricultural watershed in Poland. (2nd Joint Federal Interagency Conference, Org.). Disponível em: https://acwi.gov/sos/pubs/2ndJFIC/Contents/10E_Banasik_28_02_10.pdf. Acesso em: 2 out. 2018.

BESKOW, S. et al. Estimativa do escoamento superficial em uma bacia hidrográfica com base em modelagem dinâmica e distribuída. Revista Brasileira de Ciência do Solo, 2009. v. 33, n. 
1, p. 169-178. Disponível em: http://www.scielo.br/pdf/rbcs/v33n1/18.pdf. Acesso em: 24 mar. 2021.

CUNHA, S. F. et al. Avaliação da acurácia dos métodos do SCS para cálculo da precipitação efetiva e hidrogramas de cheia. Brasil: Revista Brasileira de Recursos Hídricos (RBRH), 2015. v. 20, n. 4, p. 837-848. Disponível em: https://abrh.s3.sa-east1.amazonaws.com/Sumarios/156/3b19fed36cf52712e217179a3483b424_fdc662cf56145d196 2c8b009e5280268.pdf. Acesso em: 29 set. 2021.

D'ASARO, F.; GRILLONE, G. Runoff Curve Number Method in Sicily: CN determination and analysis of the initial abstraction ratio. Las Vegas: [s.n.], 2010. p. 1-12. Disponível em: https://acwi.gov/sos/pubs/2ndJFIC/Contents/11E_D'Asaro_Grillone.pdf. Acesso em: $1^{\circ}$ out. 2018.

D'ASARO, F.; GRILLONE, G. Empirical investigation of Curve Number Method parameters in the mediterranean area. Journal of Hydrologic Engineering, 2012. v. 17, n. 10, p. 1141-1152. Disponível em: http://www.scopus.com/inward/record.url?eid=2-s2.084876885897\&partnerID=tZOtx3y1. Acesso em: 2 out. 2018.

ELHAKEEM, M.; PAPANICOLAOU, A. N. Estimation of the Runoff Curve Number via direct rainfall simulator measurements in the state of lowa, USA. Water Resources Management, 2009. v. 23, p. 2455-2473. Disponível em: https://link.springer.com/article/10.1007/s11269-008-9390-1. Acesso em: $1^{\circ}$ out. 2018.

ELHAKEEM, M.; PAPANICOLAOU, A. N. Runoff Curve Number and Saturated Hydraulic Conductivity Estimation via Direct Rainfall Simulator Measurements. CHI - Journal Of Water Management Modeling, 2012. p. 141-156. Disponível em: https://www.chijournal.org/R24509. Acesso em: 2 out. 2018.

EPPS, T. H. et al. Curve number derivation for watersheds draining two headwater streams in lower coastal plain south carolina, USA. Journal of the American Water Resources Association, 2013. v. 49, p. 1284-1295. Disponível em: https://www.srs.fs.usda.gov/pubs/ja/2013/ja_2013_epps_001.pdf. Acesso em: 28 jan. 2019.

FEITOSA, A. et al. Modelagem dinâmica de escoamento superficial influenciando a susceptibilidade à erosão dos solos num município do semi-árido de Pernambuco. Coimbra, Portugal: Universidade de Coimbra, 2010. p. 1-13. Disponível em: https://www.uc.pt/fluc/cegot/VISLAGF/actas/tema4/ailton. Acesso em: 29 mar. 2021.

FELIZARDO, L. M. Aplicação de Sistema de Informações Geográficas (SIG) para modelagem de eventos críticos de vazão em uma microbacia urbana. Ilha Solteira, Brasil: Universidade Estadual Paulista, 2016.2 Disponível em: https://repositorio.unesp.br/bitstream/handle/11449/144450/felizardo_Im_me_ilha.pdf?seque nce=3. Acesso em: 24 mar. 2021.

GARG, V. et al. Assessment of the effect of slope on runoff potential of a watershed using NRCSCN method. International Journal of Hydrology Science and Technology, 2013. v. 3, n. 2, p. 
141. Disponível em: http://www.inderscience.com/info/inarticle.php?artid=57626. Acesso em: 26 nov. 2018.

GUNDALIA, M.; DHOLAKIA, M. Impact of Monthly Curve Number on Daily Runoff Estimation for Ozat Catchment in India. Open Journal of Modern Hydrology,v. 4, n.4, p. 144-155, out. 2014. Disponível em: https://www.researchgate.net/publication/267098802_Impact_of_Monthly_Curve_Number_on _Daily_Runoff_Estimation_for_Ozat_Catchment_in_India/link/5c3f0755a6fdccd6b5b097e0/dow nload. Acesso em: 6 set. 2020.

HAWKINS, R. H. Asymptotic Determination of Runoff Curve Numbers from Data. Journal of Irrigation and Drainage Engineering,. v. 119, n. 2, p. 334-345, 1993. Disponível em: http://ascelibrary.org.ez122.periodicos.capes.gov.br/doi/pdf/10.1061/\%28ASCE\%2907339437\%281993\%29119\%3A2\%28334\%29. Acesso em: $1^{\circ}$ out. 2018.

HAWKINS, R. H. et al. Continuing evolution of rainfall-runoff and the curve number precedent. Las Vegas, EUA: 2nd Joint Federal Interagency Conference, p. 2-12, 2010. Disponível em: https://acwi.gov/sos/pubs/2ndJFIC/Contents/10E_Hawkins.pdf. Acesso em: $1^{\circ}$ out. 2018.

HAWKINS, R. H.; HJELMFELT, A. T.; ZEVENBERGEN, A. W. Runoff probability, storm depth, and Curve Numbers. Journal of Irrigation and Drainage Engineering, v. 111, n. 4, p. 330-340, 1985. Disponível em: https://ascelibrary.org/doi/pdf/10.1061/\%28ASCE\%2907339437\%281985\%29111\%3A4\%28330\%29. Acesso em: 28 jan. 2019.

HAWKINS, R.; KHOJEINI, A. V. Initial abstraction and loss in the Curve Number Method. Arizona, USA: Hydrology and Water Resources in Arizona and the Southwest, 2000. Disponível em: http://hdl.handle.net/10150/296552. Acesso em: $1^{\circ}$ fev. 2016.

HAWKINS, Richard H. et al. (Org.). Curve Number Hydrology - State of the Practice. Reston, Virginia: ASCE/EWRI - Environmental and Water Resources Institute (EWRI) of the American Society of Civil Engineers, 2009.

JIANG, R. Investigation of Runoff Curve Number Initial Abstraction Ratio. Arizona, EUA: School of Renewable Natural Resources, 2001. Tese. Disponível em: http://arizona.openrepository.com/arizona/handle/10150/191301. Acesso em: 5 abr. 2017.

LAL, M. et al. Evaluation of the Soil Conservation Service curve number methodology using data from agricultural plots. Hydrogeology Journal, p. 1-17, 2016. Disponível em: https://www.researchgate.net/publication/306923462_Evaluation_of_the_Soil_Conservation_S ervice_curve_number_methodology_using_data_from_agricultural_plots/link/5a05bdc1a6fdcce 984e23b7c/download. Acesso em: 9 jun. 2020.

LAL, M.; MISHRA, S. K.; PANDEY, A. Physical verification of the effect of land features and antecedent moisture on runoff curve number. Catena, v. 133, p. 318-327, 2015. Disponível em: http://dx.doi.org/10.1016/j.catena.2015.06.001. Acesso em: 2 out. 2018. 
LIM, K. J. et al. Effects of initial abstraction and urbanization on estimated runoff using CN technology. Middleburg, VA, EUA: Journal of the American Water Resources Association, $\mathrm{V}$.
42 ,
$\mathrm{n}$.
3 ,
p.
629-643,
2006.
Disponível
em:

http://www.envsys.co.kr/ envsys/paper/paper12/Effects of Initial Abstraction and Urbanization on Estimated Runoff using CN Technology.pdf. Acesso em: 26 nov. 2018.

LING, L.; YUSOP, Z. A micro focus with macro impact: Exploration of initial abstraction coefficient ratio $(\lambda)$ in Soil Conservation Curve Number (CN) methodology. [S.I.]: IOP Publishing Ltd, 2014. V. 18, p. 5. Disponível em: http://stacks.iop.org/17551315/18/i=1/a=012121?key=crossref.88cb0c455e6db3724e6a475fdd0deeb8. Acesso em: 2 ago. 2015.

MATA-LIMA, H. et al. Comportamento hidrológico de bacias hidrográficas: integração de métodos e aplicação a um estudo de caso. Ouro Preto: Rem: Revista Escola de Minas, v. 60, n. 3, p. 525-536, 2007. Disponível em: http://www.scielo.br/pdf/rem/v60n3/v60n3a14.pdf. Acesso em: $1^{\circ}$ out. 2018.

MELLO, C. R. De et al. Abstração inicial da precipitação em microbacia hidrográfica com escoamento efêmero. Campina Grande (PB): Revista Brasileira de Engenharia Agrícola e Ambiental, v. 7, p. 494-500, 2003. Disponível em: http://www.scielo.br/scielo.php?script=sci_arttext\&pid=S141543662003000300015\&lng=pt\&nrm=iso\&tlng=pt. Acesso em: $1^{\circ}$ out. 2018.

MISHRA, S. K. et al. Experimental verification of the effect of slope and land use on SCS Runoff Curve Number. Water Resources Management, v. 28, p. 3407-3416, 2014. Disponível em: https://link-springer-com.ez122.periodicos.capes.gov.br/content/pdf/10.1007\%2Fs11269-0140582-6.pdf. Acesso em: 26 nov. 2018.

MISHRA, S.; JAIN, M. K.; SINGH, V. P. Evaluation of the SCS-CN-based model incorporating antecedent moisture. Water Resources Management, v. 18, p. 567-589, 2004. Disponível em: https://www.researchgate.net/publication/226208497_Evaluation_of_the_SCS-CNBased_Model_Incorporating_Antecedent_Moisture/download. Acesso em: 25 jun. 2019.

MUSGRAVE, G. W. How much of the Rain Enters the Soil ? United States Department of Agriculture. Disponível em: https://naldc.nal.usda.gov/download/IND43894552/PDF. Acesso em: $1^{\circ}$ out. 2018.

OLIVEIRA, P. T. S. et al. Curve number estimation from Brazilian Cerrado rainfall and runoff data. Journal of Soil and Water Conservation, v. 71, n. 5, p. 420-429, 2016. Disponível em: http://www.jswconline.org/cgi/doi/10.2489/jswc.71.5.420. Acesso em: 14 nov. 2018.

PANDIT, A. et al. Estimations of Soil Conservation Service Curve Numbers for Concrete and Asphalt. Journal of Hydrologic Engineering, v. 14, n.4, p. 335-345, abril 2009. Disponível em: https://ascelibrary-org.ez122.periodicos.capes.gov.br/doi/pdf/10.1061/\%28ASCE\%2910840699\%282009\%2914\%3A4\%28335\%29. Acesso em: 2 out. 2018. 
PAULINO, P. F. Estudo sobre a sensibilidade dos parâmetros do método SCS na determinação de hidrogramas de cheia em bacias urbanas. São Carlos-SP, Brasil: Universidade de São Paulo, 2014. Disponível em: http://www.teses.usp.br/teses/disponiveis/18/18138/tde-26012015154125/\%0Ahttps://www.teses.usp.br/teses/disponiveis/18/18138/tde-26012015154125/en.php. Acesso em: 14 abr. 2021.

POMPERMAYER, R. D. C. MODELAGEM HIDROLÓGICA - técnicas de geoprocessamento aplicadas ao modelo SCS - Soil Conservation Service - Curve Number. Belo Horizonte, Brasil: Universidade Federal de Minas Gerais, 2013. Disponível em: https://repositorio.ufmg.br/handle/1843/IGCM-9QEM87. Acesso em: 24 mar. 2021.

PONCE, V. M.; HAWKINS, R. H. Runoff Curve Number: Has it reached maturity? Journal of Hydrologic Engineering, v. 1, n. 1, p. 11-19, 1996. Disponível em: http://ascelibrary.org.ez122.periodicos.capes.gov.br/doi/pdf/10.1061/\%28ASCE\%2910840699\%281996\%291\%3A1\%2811\%29. Acesso em: 26 nov. 2018.

SANTOS, S. et al. Os sistemas de informação geográfica na modelação hidrológica. In: Congreso Nacional de Tecnologías de la información Geográfica. El Acceso a la Información Espacial y Las Nuevas Tecnologías Geográficas,12. 2006. p. 465-480. Disponível em: http://tig.agegeografia.es//docs/XII_1/033 - Santos et al.pdf.

SHI, Z. H. et al. Research on the SCS-CN initial abstraction ratio using rainfall-runoff event analysis in the Three Gorges Area, China. Catena, v. 77, n. 1, p. 1-7, 2009. Disponível em: http://dx.doi.org/10.1016/j.catena.2008.11.006. Acesso em: 26 nov. 2018.

SOARES, M. R. G. De J. et al. Eficiência do método curve number de retenção de águas pluviais. Fortaleza: Revista Mercator, v. 16, n. 16001, p. 1-16, 2017. Disponível em: http://www.scielo.br/pdf/mercator/v16/1984-2201-mercator-16-e16001.pdf. Acesso em: $1^{\circ}$ out. 2018.

SOULIS, K. X.; VALIANTZAS, J. D. SCS-CN parameter determination using rainfall-runoff data in heterogeneous watersheds-the two-CN system approach. Hydrology and Earth System Sciences, v. 16, n. 3, p. 1001-1015, 2012. Disponível em: https://www.hydrol-earth-systsci.net/16/1001/2012/hess-16-1001-2012.pdf. Acesso em: 2 out. 2018.

STEWART, D.; CANFIELD, E.; HAWKINS, R. Curve Number Determination Methods and Uncertainty in Hydrologic Soil Groups from Semiarid Watershed Data. Journal of Hydrologic Engineering, v. 17, n. 11, p. 1180-1187, 2011. Disponível em: https://www.researchgate.net/publication/275182092_Curve_Number_Determination_Method S_and_Uncertainty_in_Hydrologic_Soil_Groups_from_Semiarid_Watershed_Data/download. Acesso em: 25 jun. 2019.

TEEGAVARAPU, R. S. V.; CHINATALAPUDI, S. Incorporating Influences of Shallow Groundwater Conditions in Curve Number-Based Runoff Estimation Methods. Boca Raton-FL, EUA: Water 
Resour Manage, v. 32, p. 4313-4327, 2018. Disponível em: https://link-springercom.ez122.periodicos.capes.gov.br/content/pdf/10.1007\%2Fs11269-018-2053-y.pdf. Acesso em: 2 out. 2018.

TUCCI, C. E. M. Escoamento Superficial. In: CARLOS E.M. TUCCl; ANDRÉ L.L. DA SILVEIRA ET AL. (Org.). Hidrologia: Ciência e aplicação. Porto Alegre, Brasil: Associação Brasileira de Recursos Hídricos - ABRH, 2009.

USDA-NRCS. TR-55 - Urban Hydrology for Small Watersheds. Technical Release 55. $2^{\circ}$ ed. USA: United States Department of Agriculture - Natural Resources Conservation Service, 1986.

USDA-NRCS. Land Use and Treatment Classes. Part 630 Hydrology National Engineering Handbook. USA: United States Department of Agriculture - Natural Resources Conservation Service, 2002.

USDA-NRCS. Estimation of direct runoff from storm rainfall. Part $\mathbf{6 3 0}$ Hydrology National Engineering Handbook. USA: United States Department of Agriculture - Natural Resources Conservation Service, 2004a.

USDA-NRCS. Hydrologic Soil-Cover Complexes. Part 630 Hydrology National Engineering Handbook. USA: United States Department of Agriculture - Natural Resources Conservation Service, 2004b.

USDA-NRCS. Hydrologic Soil Groups. Part 630 Hydrology National Engineering Handbook. USA: United States Department of Agriculture - Natural Resources Conservation Service, 2009.

USDA-NRCS. NRCS History | NRCS. 2016. Disponível em: http://www.nrcs.usda.gov/wps/portal/nrcs/detail/national/about/history/?cid=stelprdb104145 0. Acesso em: 21 out. 2016.

VILLARÁN SAN JUAN, R. F. DE. Mejora de los parámetros de cáculo del modelo del número de curvas y su validación medinate un modelo hidrológico distribuido. Huelva, Espanha: Universidad de Huelva - Departamento de Ciencias Agroflorestales, 2006. ISBN 978-84-9294494-1. Disponível em: http://rabida.uhu.es/dspace/handle/10272/2723. Acesso em: $1^{\circ}$ out. 2018.

WALEGA, A.; SALATA, T. Influence of land cover data sources on estimation of direct runoff according to SCS-CN and modified SME methods. Catena, v. 172, p. 232-242, jan 2019. Disponível em: https://www.sciencedirect.com/science/article/abs/pii/S0341816218303564?via\%3Dihub. Acesso em: 4 mar. 2020.

WOODWARD, D. E. et al. Runoff Curve Number Method : Examination of the initial abstraction ratio. Derwood, MD, USA: [s.n.], 2003. p. 1-10. Disponível em: http://ponce.sdsu.edu/hawkins_initial_abstraction.pdf. Acesso em: $1^{\circ}$ out. 2018. 
WOODWARD, D.E. et al. Curve number method: Origins, applications and limitations. Disponível em: https://www.wcc.nrcs.usda.gov/ftpref/wntsc/H\&H/CNarchive/CNorigins.doc. Acesso em: $1^{\circ}$ out. 2018.

YUAN, Y. et al. Initial abstraction and curve numbers for semiarid watersheds in Southeastern Arizona. Hydrological Processes, v. 28, n. 3, p. 774-783, 2014. Disponível em: http://onlinelibrary.wiley.com/doi/10.1002/hyp.9592/pdf. Acesso em: $1^{\circ}$ out. 2018.

\section{1 - Fabio Carvalho:}

Professor de geografia do IFG Campus Goiânia, https://orcid.org/0000-0001-8656-1607 - carvalhofabiogeo@gmail.com Contribuição: revisão de literatura e redação.

\section{2 - Silvio Carlos Rodrigues:}

Professor no Curso de Geografia da Universidade Federal de Uberlândia, https://orcid.org/0000-0002-5376-1773 - sigel@ufu.br

Contribuição: organização e revisão do texto.

\section{Como citar este artigo}

CARVALHO, F.; RODRIGUES, S. C. Método Curve Number - pesquisas e discussões dos parâmetros valor CN e abstração inicial. Geografia Ensino \& Pesquisa, Santa Maria, v. 25, e31, p. 1-50, 2021. DOI 10.5902/2236499447861. Disponível em: https://doi.org/10.5902/2236499447861. Acesso em: dia mês abreviado. ano. 